\title{
Synthesis, Kinetic Analysis and Modelling of Galacto-Oligosaccharides Formation
}

\author{
I. Mueller $^{1 *}$, G. Kiedorf ${ }^{2}$, E. Runne ${ }^{1}$, A. Seidel-Morgenstern ${ }^{2,3}$, C. Hamel ${ }^{1,3}$ \\ ${ }^{1}$ Anhalt University of Applied Sciences, Applied Biosciences and Process Engineering, Bernburger Str. 55, D-06366 Koethen, Germany \\ ${ }^{2}$ Max Planck Institute for Dynamics of Complex Technical Systems, Sandtorstr. 1, D-39106 Magdeburg, Germany \\ ${ }^{3}$ Otto von Guericke University, Institute of Process Engineering, Universitätsplatz 2, D-39106 Magdeburg, Germany \\ *Corresponding author: phone: +49-3496-672569, e-mail: ines.mueller@hs-anhalt.de
}

\section{Highlights}

- Kinetic analysis of galacto-oligosaccharides (GOS) formation from lactose in a broad range of operating parameters

- Static and dynamic perturbation experiments performed to identify inhibition effects and reaction network

- Catalytic cycle postulated and mechanistic kinetic models for GOS synthesis based on Christiansen methodology derived

- Sensitivity analysis by parameter reduction techniques performed to reduce kinetic models to sensitive parameters only

- Model validation successful, provides basis for process development and optimization

\section{Graphical Abstract}

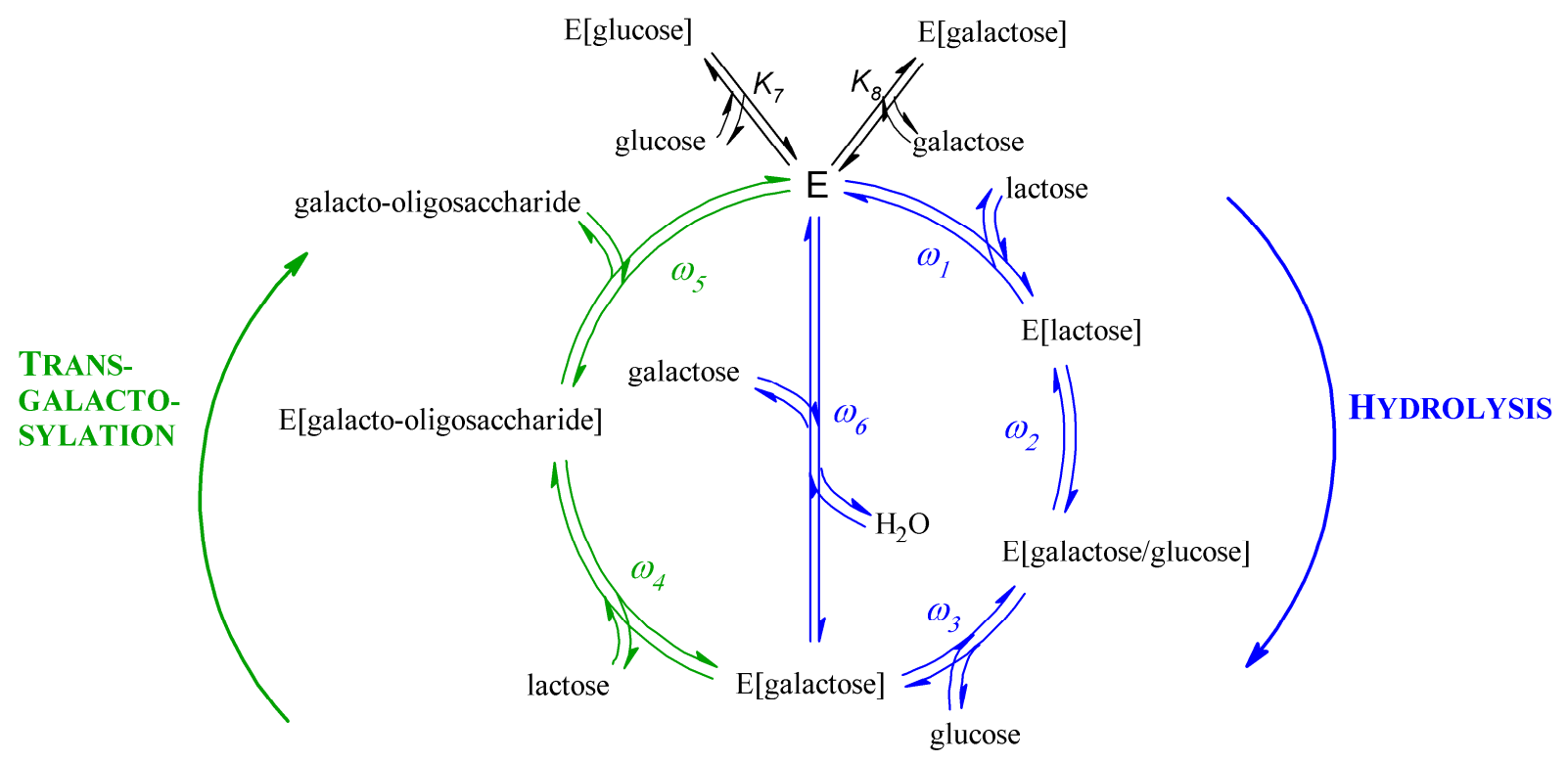

$\underline{\text { Keywords }} \beta$-Galactosidase; Perturbation experiments; Network analysis; Mechanistic kinetics; Parameter reduction and estimation; Modelling

\section{Abstract}


To design and optimize chemical reactors and bio reactors a profound understanding of kinetics and in particular suitable mechanistic rate models is needed. In chemical reaction engineering the methodology from Christiansen considering elementary kinetics assuming rate-determining steps has been successfully applied. It is hardly considered for enzymatic reactions. In this work, kinetics of formation of the prebiotics galacto-oligosaccharides (GOS) from lactose were investigated with $\beta$-galactosidase using batch and dynamic experiments. The rates of the main and most relevant side reactions were quantified. Preliminary investigations were performed to determine the influence of $\mathrm{pH}$, temperature, the amount of enzyme and the initial lactose concentration. To acquire mechanistic understanding instructive perturbation experiments were carried out dosing the substrate lactose and/or the products galactose and glucose either initially or dynamically during fermentation. Based on a postulated catalytic cycle, mechanistic kinetic models were developed considering hydrolysis of lactose, formation of GOS and inhibiting effects of the side products glucose and galactose. A sensitivity analysis was performed applying the subset selection method including model reduction based on singular value decomposition combined with rank revealing QR factorization. The parameterized mechanistic models allowed a good description of batch and dynamic experiments in a broad range of operating conditions. 


\section{Introduction}

Due to the growing health consciousness of consumers galacto-oligosaccharides (GOS) with their promising health benefits offer an increasing market interest (Lamsal, 2012). GOS are widely established as prebiotic ingredient as the effect was proven by several in vivo and in vitro studies (Alander et al., 2001; Davis et al., 2010; Ito et al., 1990; Shadid et al., 2007). Prebiotics by definition are non-digestible food ingredients that selectively stimulate the intestinal bifidobacteria and contribute to an improved gut activity of the consumer (Roberfroid et al., 2010). The term non-digestibility of prebiotics comes along with a low caloric value of oligosaccharides which is estimated to be in a range between 1 and $2 \mathrm{kcal} \mathrm{g}^{-1}$ (Roberfroid et al., 1993). According to various studies GOS assumes to enhance the mineral resorption and bone mineralization (Chonan et al., 1995; van den Heuvel et al., 2000). Furthermore, GOS are characterized as non-cariogenic (Sako et al., 1999) and possesses a relative sweetness of 0.3-0.6 regarding to sucrose (Playne and Crittenden, 2009; Tzortzis and Vulevic, 2009). On the other hand GOS provide valuable physicochemical properties like thermal as well acid-stability under certain conditions (Sako et al., 1999) and a high water binding capacity (Playne and Crittenden, 2009; Tzortzis and Vulevic, 2009). The functionality of GOS leads to a broad range of product applications such as confectionery, jams, baked goods, beverages and fermented milk products (Affersholt-Allen, 2007; Schoterman, 2007). However, the prebiotic properties of GOS are of main interest for its use in the field of infant and elderly nutrition (Sako et al., 1999; Sangwan et al., 2011). The prebiotic effect and other physical and functional properties respectively are defeated by the reliance on the composition of each GOS product (Playne and Crittenden, 2009).

GOS can be synthesized from lactose by the enzyme $\beta$-galactosidase ( $\beta$-gal). As lactose is a largely arising by-product of cheese production there is a great demand for exploitation and improvement of economic aspects (Gänzle et al., 2008; Geiger et al., 2016; Guimarães et al., 2010). One promising opportunity for utilization with added value is the enzymatic formation of prebiotic GOS. The resulting product mixture contains GOS of different chain lengths, unreacted lactose and the side products galactose and glucose. Depending on the enzyme species as well as the process parameters, like temperature, $\mathrm{pH}$ value and initial lactose concentration GOS with different glycosidic bonds, chain lengths and yields can be achieved (reviewed by (Sangwan et al., 2011; Torres et al., 2010)). Especially high yields are of particular interest for an efficient manufacturing process. Thus, an experimental and model 
based study of enzyme kinetics in a broad range of operation conditions builds an essential fundament for a suitable process optimization.

This contribution focuses on the development of a mechanistic kinetic model with assumption of rate-determining steps for GOS synthesis based on a catalytic cycle for the enzyme $\beta$-galactosidase from Escherichia coli. Dynamic perturbation experiments will be performed to provide detailed information about the reaction network and the sensitivity of kinetic parameters. Inhibition effects of the reaction as well as limitation by chemical equilibrium are embedded to obtain an all-embracing reaction model of the GOS formation kinetics.

The kinetic analysis performed in this paper is based on a very general approach originally suggested by Christiansen (Christiansen, 1953; Helfferich, 2004; Murzin and Salmi, 2005). This approach quantifies in a very general way catalytic cycles and provides explicit expressions in a generic way. Several authors have demonstrated the potential of the Christiansen methodology investigating various reaction systems (Helfferich, 2004; Marin and Yablonsky, 2011; Murzin and Salmi, 2005). This approach assumes pseudo-first order rate laws for all elementary steps, which are considered as reversible and without ratedetermining assumptions and includes explicitly one catalyst species. Thus, a general equilibrium limited rate approach without rate determining step is obtained.

Due to a large number of unknown kinetic parameters arising from the mechanistically rate law, suitable model reduction techniques such as the subset selection method are needed (Burth et al., 1999; Fink et al., 2007). The subset selection method allows the identification of ill-conditioned parameter subsets in order to exclude the parameters from the estimation task. As a result, a reduced model with estimable parameters can be suggested. This method was successfully demonstrated for different problems (Barz et al., 2013; Fink et al., 2007; Jörke et al., 2015; Kiedorf et al., 2014; Kiedorf et al., 2016). However, the determinability of kinetic parameters depends on the experimental data as well. In this work, batch, dynamic and static perturbation experiments will be performed.

In this contribution initially the concrete reaction system, reactor model and tools for deriving in general mechanistic kinetic models based on catalytic cycles will be introduced. After describing batch experiments to study the influence of $\mathrm{pH}$ value, temperature, lactose and enzyme concentration as well as side products an optimized operating point for kinetic investigations will be set. A specific reaction network, a catalytic cycle and corresponding mechanistic models will be derived. A model reduction will be carried out based on 
instructive dynamic perturbations, which are required to identify reliable reaction rate laws and parameters. Finally, for all key reactions of the network rate equations and corresponding parameters are provided and discussed. Thus, a detailed understanding of the reaction kinetics and the reaction network in a broad range of operation conditions will be provided to design, scale-up and optimize the industrial GOS production.

\section{Theory: Reaction network, catalytic cycle and model formation}

\subsection{Recent depictions of GOS synthesis}

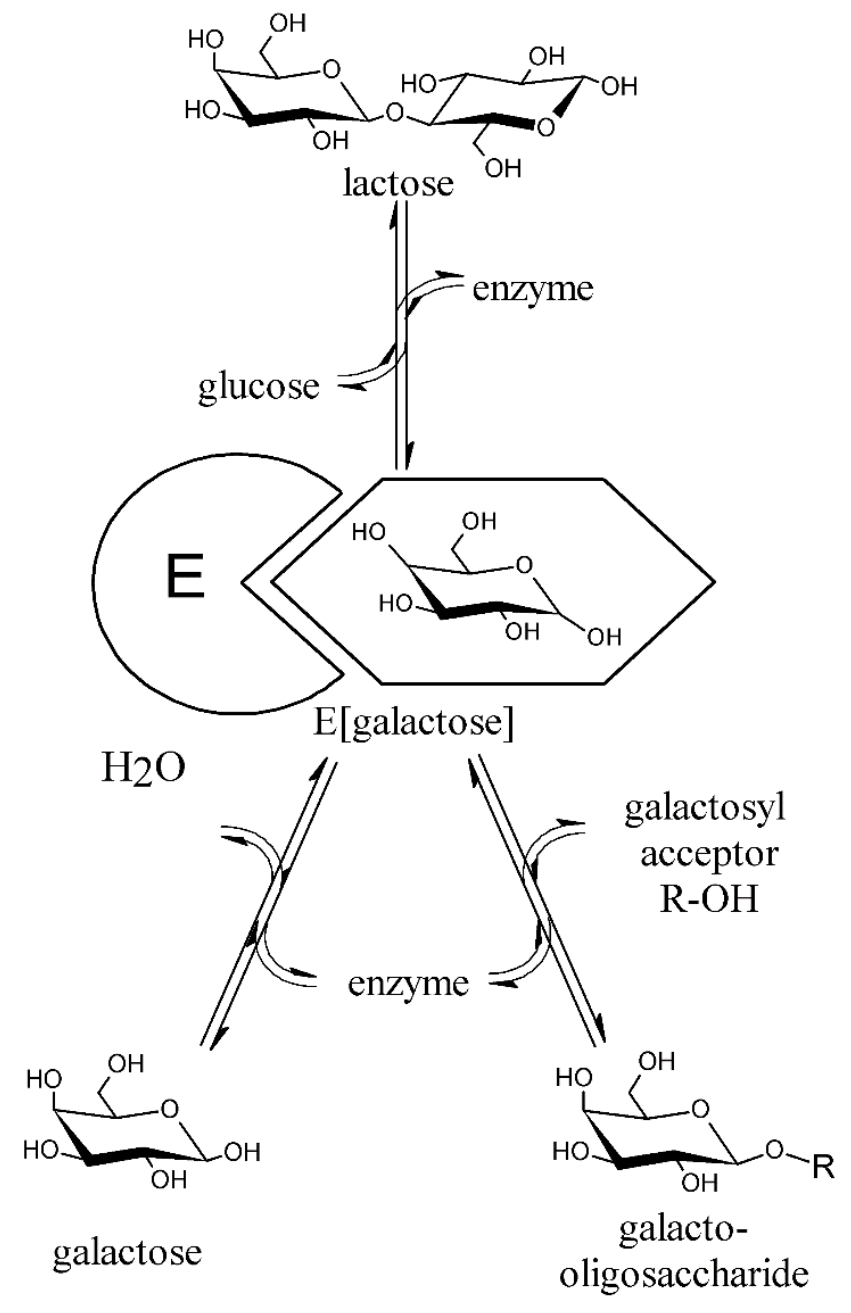

Figure 1: Two step reaction mechanism of GOS synthesis; first step: formation of a covalently bound enzymegalactose-complex; second step: hydrolysis with water to galactose (left side) or transgalactosylation reaction with a galactosyl acceptor of a sugar molecule to a galacto-oligosaccharide as reported by (Fischer and Kleinschmidt, 2015; Torres et al., 2010)

Formation of galacto-oligosaccharides is a fermentation process catalysed e. $\mathrm{g}$. by the enzyme $\beta$-galactosidase ( $\beta$-D-galactoside galactohydrolase, E.C. 3.2.1.23) (Intanon et al., 2014). Main 
substrate for synthesis is lactose which is formed to galactopyranosyl oligomers with an optional terminal glucose - molecule and different degrees of polymerization (DP, n: 2-8) (Mahoney, 1998; Tzortzis and Vulevic, 2009).

In literature the reaction mechanism is mostly described as a simple two-step procedure as illustrated in Figure 1 (Intanon et al., 2014; Sangwan et al., 2011; Torres et al., 2010). In the first step a covalent galactosyl-enzyme-complex (E[galactose]) is built as intermediate. In a subsequent second step hydrolysis occurs when water serves as glycosyl acceptor and galactose is formed. Otherwise a transgalactosylation proceeds whereat the galactosylated enzyme reacts with the hydroxyl group of another sugar in solution resulting in a galactooligosaccharide. Galactosyl acceptor $(\mathrm{R}-\mathrm{OH})$ of the transgalactosylation can be glucose in an intramolecular reaction and/or galactose, lactose or GOS as in an intermolecular reaction. Hydrolysis and transgalactosylation are described in literature as competing and kinetically controlled reactions inducing a heterogeneous mixture containing monosaccharides (glucose, galactose), unreacted lactose and GOS with different regiochemical structures and number of monomers (Tzortzis and Vulevic, 2009).

For mathematical description and modelling of the GOS formation process, the simplistic Michaelis-Menten kinetics are chosen by several authors by default. Chen et al. (2003) depicted the process as a seven-step-nine-parameter reaction mechanism for $\beta$-gal from Escherichia coli in reverse micells. Whereas (Kim et al., 2004) proposed a five-step-nineparameter system for $\beta$-gal from Kluyveromyces lactis in a free enzyme system and Palai et al. (2016) were developing over several contributions also a five-step-nine-parameter reaction system for $\beta$-gal from Bacillus circulans ranging from a reaction system with free enzyme, immobilized enzyme or enzyme bioconjugation. All models include the hydrolysis reaction and differ mostly in the chosen galactosyl acceptor forming either allolactose, GOS DP3 or perhaps GOS DP4. One other main aspect is the inhibition by either galactose, glucose, both or none. In conclusion, the chosen Michaelis-Menten kinetic is restricted operation conditions only and do not provide the possibility for further predictions and coupled inhibition mechanism, respectively. However, in this contribution the presented mechanistic kinetic model is a new and beneficial approach to the modelling of the GOS formation process. As the GOS synthesis is described in literature as an equilibrium limited reaction with inhibitory effects of the side products glucose and/or galactose, these aspects have to be proven experimentally in chapter 5 for the studied system and included in the system specific catalytic cycle and into the mechanistic kinetic models, respectively. Nevertheless, the reaction network reported in literature have not been developed for a broad range of operating 
conditions and always include rate determining steps. Thus, a more general approach should be developed in this contribution.

\subsection{Constitution of a catalytic cycle}

The mathematical fundamentals of a uniform derivation of the isolated reaction rate approaches were already given by Christiansen in the 1930's and used till now often in chemical reaction engineering (Christiansen, 1953; Helfferich, 2004; Marin and Yablonsky, 2011). This general approach will be applied in this contribution for an enzyme catalysed reaction. This concept assumes pseudo-first order rate laws for all elementary steps and includes explicitly one catalyst species. More than one catalyst species involved in the catalytic cycle (Fig. 2) cannot be handled by the Christiansen approach. The general reaction rate formula of a $N_{\text {step }}$ catalytic cycle considering an external pathway at one catalyst species is given by eq. 1 (Helfferich, 2004; Murzin and Salmi, 2005). By means of using the individual forward (+) and backward (-) cycle step frequencies $\omega_{j \omega}$ the pseudo-first order rate assumption is achieved. For example, the forward frequency of the first catalytic cycle step $\omega_{1}{ }^{+}$(see Fig. 2) is defined by the product of the forward frequency factor $k_{1}{ }^{+}$and the reactant concentration $c_{\mathrm{A}}\left(\omega_{1}{ }^{+}=k_{1}{ }^{+} c_{\mathrm{A}}\right)$. The total catalyst concentration $c_{\text {cat }}$ yields from the sum of all intermediate catalyst/enzyme concentrations. The denominator $\Omega$ corresponds to the Christiansen matrix and consider each intermediate catalyst species concentration. The composition of the matrix for a three-step catalytic cycle follows eq. 2.

$$
r=\frac{\left(\prod_{j_{\omega}=1}^{N_{\text {step }}} \omega_{j_{\omega}}^{+}-\prod_{j_{\omega}=1}^{N_{\text {step }}} \omega_{j_{\omega}}^{-}\right) \cdot c_{\text {cat }}}{\Omega+\Omega_{j_{\text {inh }} j} K_{\text {inh }} c_{\text {inh }}}
$$

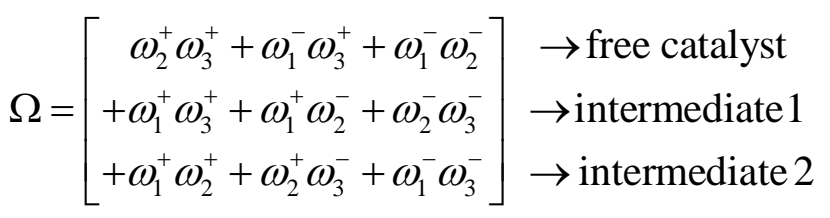

The rigorous derivation of the Christiansen matrix $\Omega$ is laborious. However, it can be seen how the matrix develops. If the free catalyst is considered as inactive and all other catalytic cycle steps are very fast and therefore approximated by the Bodenstein principle, the Christiansen matrix can be reduced to the first row. But nothing distinguishes the free catalyst species mathematically from the other cycle members. Thus, all catalyst species can be present as free catalyst. Accordingly, the derivation of the intermediate 1 matches the second row of the Christiansen matrix et cetera. Based on this, the sum of the elements of each row is proportional to the concentration of one catalyst species in the catalytic cycle involved (see Fig. 2 and eq. 2). More information can be found in Helfferich (2004) and in the appendix of this manuscript. 
Inhibition effects by catalyst poison or any substance that reduces the active catalyst amount are considered by second term in the denominator $\Omega_{j \text { inhj }} K_{\text {inh }}{ }^{*} c_{\text {inh. }} . \Omega_{j i n h j}$ is the sum of the row elements of the Christiansen matrix for the cycle, where the external pathway is connected with the catalytic cycle and $K_{\text {inh }}$ the equilibrium constant of active catalyst loss (Helfferich, 2004).

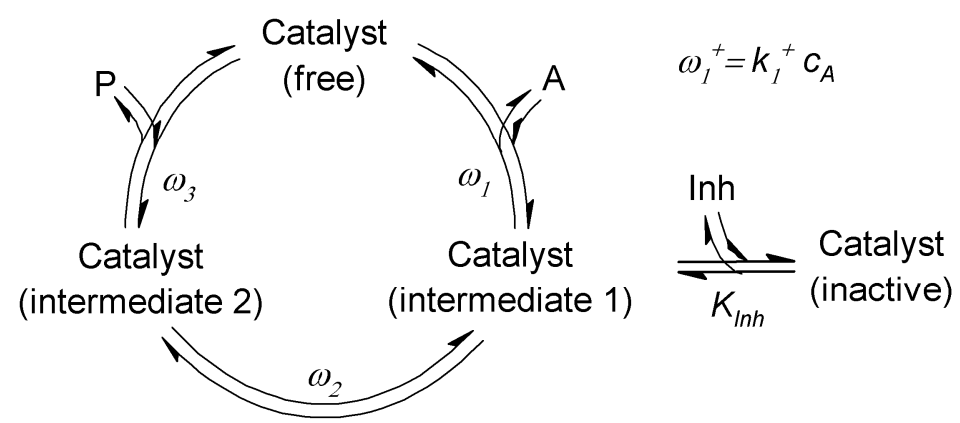

Figure 2: General three step catalytic cycle considering one external pathway at intermediate 1 and suggestion of the definition of the catalytic cycle step frequencies

\subsection{Reactor model, parameter estimation and Subset-Selection method}

The evaluation of the concentration profiles versus reaction time was performed considering the applied tank reactor model as perfectly mixed and including perturbations. It was further assumed that the reactions take place exclusively in the well mixed liquid phase neglecting mass transfer limitations. The corresponding partial mass balance for a component $i$ is shown in eq. 3. The related units of each variable used is presented at the nomenclature.

$$
\frac{d c_{\mathrm{i}}}{d t}=\frac{m_{\mathrm{cat}}}{V_{\mathrm{R}}} \cdot \sum_{j=1}^{N_{\mathrm{R}}} v_{\mathrm{j}, \mathrm{i}} \cdot r_{\mathrm{j}}\left(T, c_{\mathrm{i}}\right)+\frac{n_{\mathrm{i}}^{\mathrm{dos}}}{V_{\mathrm{R}}} \quad \text { with } \quad \frac{d c_{\mathrm{tot}}}{d t}=\sum_{i=1}^{N_{\mathrm{C}}} \frac{d c_{\mathrm{i}}}{d t}
$$

In this equation are $N_{\mathrm{C}}$ components and $N_{\mathrm{R}}$ reactions assumed taking place in the liquid phase. The introduction and derivation of the used mechanistic rate approaches $r_{\mathrm{j}}\left(T, c_{\mathrm{i}}\right)$ based on a catalytic cycle is part of section 6 . For solving the ordinary differential equation, the initial condition is required (eq. 4).

$$
c_{\mathrm{i}}(t=0)=c_{\mathrm{i}}^{0}
$$

The kinetic parameter estimation problem was solved using a trust-region-reflective algorithm, which is implemented in the optimization solver lsqnonlin of MATLAB 8.6.0 (R2015b). The estimation procedure was carried out in two steps. First, initial values were generated at an isothermal regression at each of the experimental investigated temperatures. The second step includes a non-isothermal regression based on the initial values of the first 
regression (Toch et al., 2015). The used objective function $O F$ follows the sum of least squares method (eq. 5).

$$
O F\left(\Theta_{\mathrm{opt}}\right)=\sum_{j_{\mathrm{obs}}=1}^{N_{\mathrm{obs}}}\left(c_{j_{\mathrm{obs}}}^{\exp }\left(c_{\mathrm{i}}^{0}\right)-c_{j_{\mathrm{obs}}}^{\mathrm{mod}}\left(c_{\mathrm{i}}^{0}, \Theta_{\mathrm{opt}}\right)\right)^{2}
$$

However, also in combination of these two regressions strong parameter correlations may occur. As a consequence, the analysis of experimental data causes ill-posed inverse parameter estimation problems and tends to give parameter values with huge confidence intervals. To avoid such parameter correlation, the introduced subset-selection works as follows. Standard optimization algorithm minimizes a quadratic approximation of the objective function using a Taylor series. In order to solve the next iteration step of the optimization algorithm, the second derivation of the objective function has to be invertible. It is generally known that the Hessian matrix is not singular if the rank of Jacobian is full (Jörke et al., 2015; Kiedorf et al., 2014). The Jacobian matrix presents the first derivation of the residual with respect to the optimization parameters and is also known as sensitivity matrix. By means of this matrix the sensitivity analysis is classified in the singular-value-decomposition (svd) and QRdecomposition. The svd identifies the number of well-conditioned parameters. In the QRdecomposition the sensitivity matrix is sorted in a way that the singular values decrease sequentially (Jörke et al., 2015; Kiedorf et al., 2014). Thus, a sensitive parameter subset is revealed.

\section{Experimental}

\subsection{Chemicals and analytical methodology}

Chemicals for synthesis and analytics like lactose monohydrate (purity $\geq 99.5 \%$ ), $\mathrm{D}(+)$-glucose monohydrate (purity $\geq 99.5 \%$ ), $\mathrm{D}(+)$-galactose (purity $\geq 98 \%$ ), di-sodium hydrogen phosphate dehydrate $\left(\mathrm{Na}_{2} \mathrm{HPO}_{4} \cdot 2 \mathrm{H}_{2} \mathrm{O}\right.$; purity $\left.\geq 99.5 \%\right)$, di-potassium hydrogen phosphate $\left(\mathrm{KH}_{2} \mathrm{PO}_{4}\right.$; purity $\left.\geq 99.5 \%\right)$ as well magnesium chloride $\left(\mathrm{MgCl}_{2}\right.$, purity $\left.\geq 98.5 \%\right)$ were acquired from Carl Roth $\mathrm{GmbH}+\mathrm{Co}$. KG (Karlsruhe, Germany). The enzyme preparation $\beta$-galactosidase from Escherichia coli as lyophilized powder was purchased from Sigma-Aldrich (article 48275, Taufkirchen, Germany).

The quantification of synthesis products was conducted with the high-performance liquid chromatography system "VWR Hitachi Chromaster" (VWR International GmbH, Darmstadt, Germany). For carbohydrate analysis, the column "NUCLEODUR 100-5 $\mathrm{NH}_{2}-\mathrm{RP}$ (250x4 $\mathrm{mm}$ )" from MACHEREY-NAGEL GmbH \& Co. KG (Düren, Germany) was utilized. 
Samples with an injection volume of $25 \mu \mathrm{L}$ were eluted isocratic with acetonitrile/water $80: 20(\% \mathrm{v} / \mathrm{v})$ at a volumetric flow rate of $2 \mathrm{~mL} \mathrm{~min}^{-1}$. Acetonitrile (purity $\geq 99.9 \%$ ) as HPLC eluent was purchased from VWR International GmbH (Germany). The column was maintained at $25{ }^{\circ} \mathrm{C}$. The overall run time of one sample amounted 40 minutes. The separation signal was detected by a refractive index detector at $40^{\circ} \mathrm{C}$. For quantification of GOS a certified DOMO ${ }^{\circledR}$ Vivinal $^{\circledR}$ GOS Syrup (article 596667) was kindly provided by Friesland Campina (Amersfoort, The Netherlands) and obtains a composition of $44.25 \%$ GOS, $15 \%$ lactose, $15 \%$ glucose, $1.05 \%$ galactose and $24.7 \%$ water (mass fractions). Glucose, galactose and lactose were calibrated separately by standards as described above. For the GOS calibration the DOMO ${ }^{\circledR}$ Vivinal $^{\circledR}$ GOS Syrup was injected on the column at several defined mass concentrations $\left(\mathrm{g} \mathrm{L}^{-1}\right)$. Within the obtained chromatogram from the syrup the elution times of the substances lactose, glucose and galactose were identified by their standard solutions. The chosen chromatographic method does not provide information of individual GOS species. Due to the fact, that no other impurities are documented in the analysis and certificate of the GOS syrup supplier the remaining peaks were lumped together as one pseudo species GOS. Thus, the peak areas were summarized for one GOS calibration response factor.

The integration of the components was performed by the software Agilent OpenLAB CDS EZChrom Edition (Agilent Technologies, Inc.).

\subsection{Synthesis of GOS}

The initial amounts of lactose were diluted in phosphate buffer which got mixed from $0.1 \mathrm{~mol}$ $\mathrm{L}^{-1} \mathrm{Na}_{2} \mathrm{HPO}_{4}$ and $0.1 \mathrm{~mol} \mathrm{~L} \mathrm{KH}_{2} \mathrm{PO}_{4}$ for $\mathrm{pH}$ adjustment. $1 \mathrm{mmol} \mathrm{L} \mathrm{MgCl}_{2}$ was added for enzyme stabilization (Sigma-Aldrich Inc., 2005). One reaction mixture in a flask comprised $25 \mathrm{~mL}$ which got tempered in an "Incubating Minishaker" (VWR International GmbH, Darmstadt, Germany) with a shaking frequency of $300 \mathrm{rpm}$. Aliquot enzyme solutions were added with absolute masses of $0.731 \mathrm{mg}$ for $4.5 \mathrm{U} \mathrm{mL}^{-1}, 1.461 \mathrm{mg}$ for $9 \mathrm{U} \mathrm{mL}^{-1}$ and $2.273 \mathrm{mg}$ for $14 \mathrm{U} \mathrm{mL}^{-1}$. The initial enzyme activity of $154 \mathrm{U} \mathrm{mg}^{-1}$ was tested with a product specific enzyme activity assay provided by Sigma-Aldrich with o-nitrophenyl $\beta$-D-galactoside as substrate. After dosage of the enzyme the reaction took place and was analysed for 24 hours. Samples for HPLC analysis were taken after 0/0.25/0.5/1/2/4/6/24 h. The inactivation of the enzymes after reaction was obtained through immersing the samples for three minutes into a $90{ }^{\circ} \mathrm{C}$ hot water bath. For perturbation experiments, additional amounts of glucose or galactose $\left(10 \mathrm{~g} \mathrm{~L}^{-1}\right.$ or $\left.50 \mathrm{~g} \mathrm{~L}^{-1}\right)$ were subjoined to the reaction mixture before start of 
synthesis for static inhibition and during synthesis (30 min after start) for dynamic inhibition. For GOS, glucose and galactose the yield is defined by the product mass concentration divided by the initial substrate mass concentration in percent.

\section{Preliminary experimental studies}

In the following results of a performed preliminary feasibility study were presented to investigate the influence of $\mathrm{pH}$ value, temperature, lactose and enzyme concentration and byproducts in order to adjust an optimized operating point with respect to kinetic modelling.

\subsection{Effects of temperature and $\mathrm{pH}$ value}

Two of the most significant aspects for enzymatic synthesis are temperature and $\mathrm{pH}$ value (Boon et al., 2000; Martínez-Villaluenga et al., 2008). Numerous investigations on process parameters such as temperature and $\mathrm{pH}$ of different $\beta$-gal enzyme species have been summarized and reviewed by Vera et al. (2016) and Torres et al. (2010), inter alia. It becomes apparent that for one species the optimal temperature and $\mathrm{pH}$ can differ, mostly depending on the reaction system with free or immobilized enzyme. Only two authors provide information for $\beta$-galactosidase from E. coli (Chen et al., 2003; Huber et al., 1976) and will be compared in the following with the results of this contribution.

Figure 3 shows the effect of the $\mathrm{pH}$ value on the GOS formation for the enzyme species $\beta$ galactosidase from E. coli. Synthesis was performed at six different $\mathrm{pH}$ values: 5.5, 6.5, 7.0, 7.4, 7.7 and 8.0. Optimal GOS yield regarding lactose conversion was identified at $\mathrm{pH} 7.0$ and $\mathrm{pH} 7.4$ with highest measured GOS yield of $42 \%$ at pH 7.0 after 24 hours. At lower and higher $\mathrm{pH}$ values the GOS yield markedly decreases over lactose decomposition and implies higher hydrolysis than transgalactosylation activity of the enzyme especially at $\mathrm{pH}<7.0$. Similar observations were reported by Huber et al. (1976), who evinced highest GOS formation rate at $\mathrm{pH}$ 7.2/7.3. Whereas Chen et al. (2003) described best GOS formation ratio for the enzyme species (in reverse micelles) at $\mathrm{pH} 6.5$ with $44 \%$ (w/w) GOS (di-, tri-, tetrasaccharides). The overall GOS formation in these $\mathrm{pH}$ ranges also induces significantly lower yields than at $\mathrm{pH} 7.0$ and $\mathrm{pH} 7.4$ in relation to the reaction duration of $24 \mathrm{~h}$. 


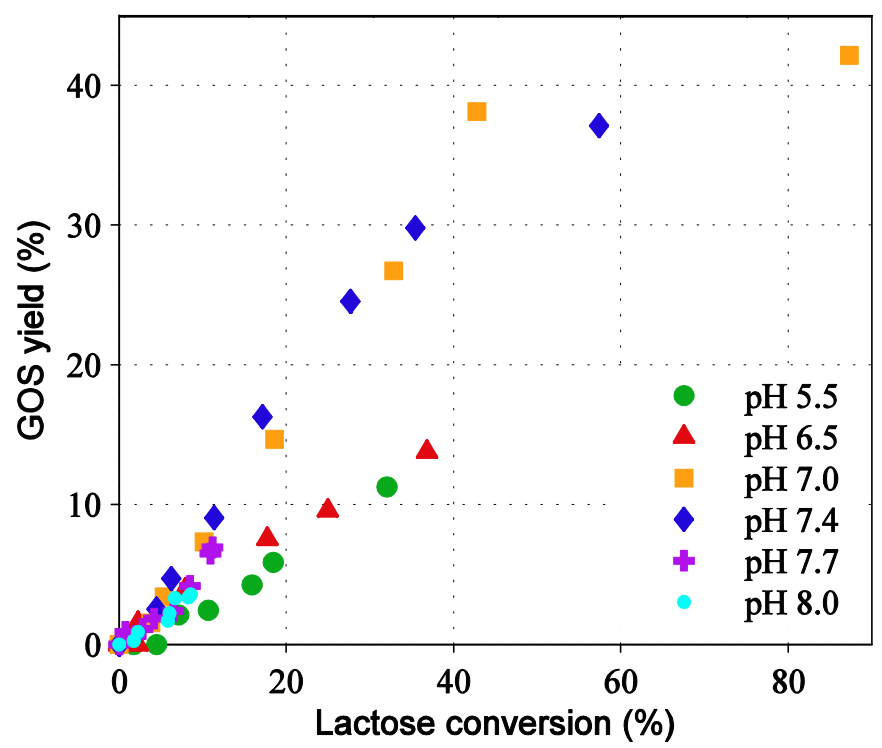

Figure 3: Influence of the $\mathrm{pH}$ value to GOS yield versus lactose conversion, ILC $=100 \mathrm{gL}^{-1}$, $m_{\text {Cat }}=4.5 \mathrm{U} \mathrm{mL}^{-1}, 40{ }^{\circ} \mathrm{C}$, data points present samples taken in an interval of 0/0.25/0.5/1/2/4/6/24 hours (order with rising lactose conversion)

Figure 4 represents the ratio of GOS yield to lactose conversion in relation to the reaction temperature. Estimation of the effect of fermentation temperatures were performed in a range of $10{ }^{\circ} \mathrm{C}$ to $60{ }^{\circ} \mathrm{C}$ with an interval of $10 \mathrm{~K}$. The enzyme activity towards higher GOS formation rate reveals an optimal reaction temperature at $30^{\circ} \mathrm{C}$ and $40{ }^{\circ} \mathrm{C}$. At lower and higher temperatures, the enzyme species possesses changed kinetics with higher hydrolysis reaction rates than transgalactosylation occurs. Chen et al. (2003) also researched the influence of temperature on GOS synthesis with the enzyme $\beta$-galactosidase from E. coli, who determined GOS yields between $37{ }^{\circ} \mathrm{C}$ and $53{ }^{\circ} \mathrm{C}$ in the same system as described above. It was found that temperatures $>37{ }^{\circ} \mathrm{C}$ result in larger amounts of allolactose (GOS DP2) combined with a simultaneous inhibition of GOS formation with higher DP. Chen et al. (2003) observed after $1 \mathrm{~h}$ at $53{ }^{\circ} \mathrm{C}$ no further GOS production which was implied to an inactivation of the enzyme while this study shows even at $60^{\circ} \mathrm{C}$ an ongoing lactose conversion over 24 hours fermentation but with a disrupted GOS production. 


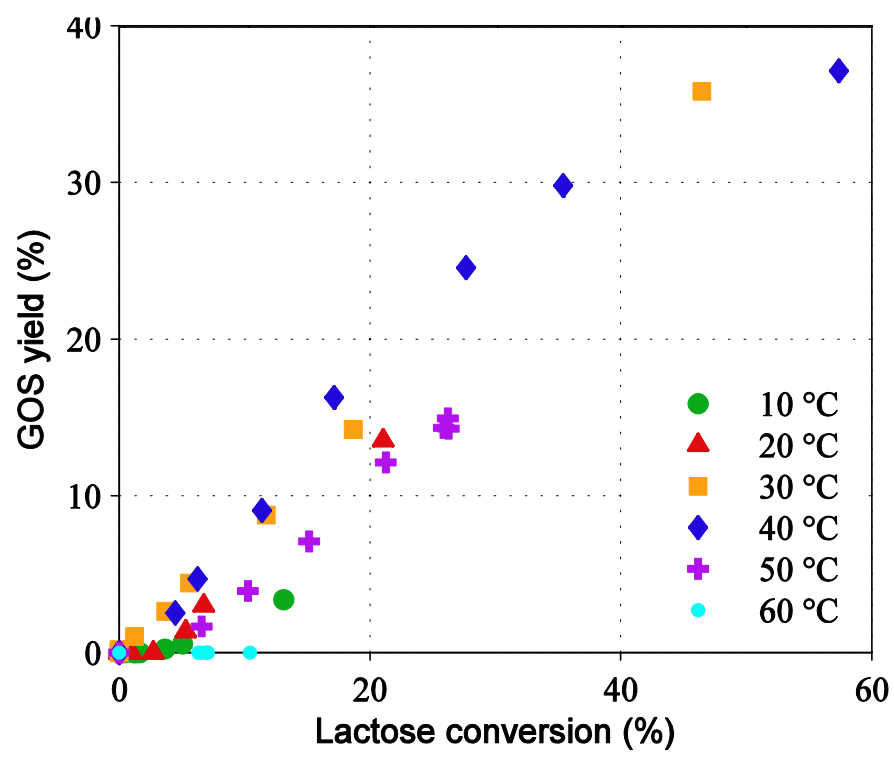

Figure 4: Development of GOS yield versus lactose conversion at different temperatures with an enzyme concentration of $4.5 \mathrm{U} \mathrm{mL}^{-1}$, ILC $100 \mathrm{~g} \mathrm{~L}^{-1}$, pH 7.4, data points present samples taken in an interval of $0 / 0.25 / 0.5 / 1 / 2 / 4 / 6 / 24$ hours (order with rising lactose conversion)

\subsection{Effect of initial lactose and enzyme concentration}

In favour of a better economic operating, kinetics and process improvement the effects of enzyme concentration and initial lactose concentration to GOS formation were determined (see fig. 5). Enzyme concentration was varied between $4.5 \mathrm{U} \mathrm{mL}^{-1}, 9 \mathrm{U} \mathrm{mL}^{-1}$ and $14 \mathrm{U} \mathrm{mL}^{-1}$ and initial lactose concentration was determined at $25 \mathrm{~g} \mathrm{~L}^{-1}, 50 \mathrm{~g} \mathrm{~L}^{-1}, 100 \mathrm{~g} \mathrm{~L}^{-1}$ and $150 \mathrm{~g} \mathrm{~L}^{-1}$. It becomes clear that the enzyme amount has no significant influence to the yield/conversion ratio for the conditions experimentally studied. However, at identical enzyme concentration an increase of the yields in relation to lactose conversion with higher initial lactose concentration (ILC) was observed. The increase of transgalactosylation with lactose concentration is in accordance with observations by other authors before (MartínezVillaluenga et al., 2008; Neri et al., 2009). In comparison of the plots A to D of figure 5 maximum GOS yield can be observed between $60 \%$ and $80 \%$ lactose conversion. Higher conversion rates result in a reduction of GOS. This dependency was described by several authors as a low lactose to water content ratio leads to a higher hydrolysis activity (Neri et al., 2009; Prenosil et al., 1987; Smart, 1991). A low lactose concentration related to the enzyme concentration induces lower availability for the substrate to operate as galactosyl acceptor in the formation of higher GOS species (see fig.1). Put it another way, the probability for water being the galactosyl acceptor is much higher and accelerates the hydrolysis activity of the system. 
The overall highest GOS yield with $49.05 \%$ was reached after six hours reaction time at $\mathrm{pH}$ 7.4, $40{ }^{\circ} \mathrm{C}, 14 \mathrm{U} \mathrm{mL}^{-1}$ enzyme concentration and an initial lactose concentration of $150 \mathrm{~g} \mathrm{~L}^{-1}$.
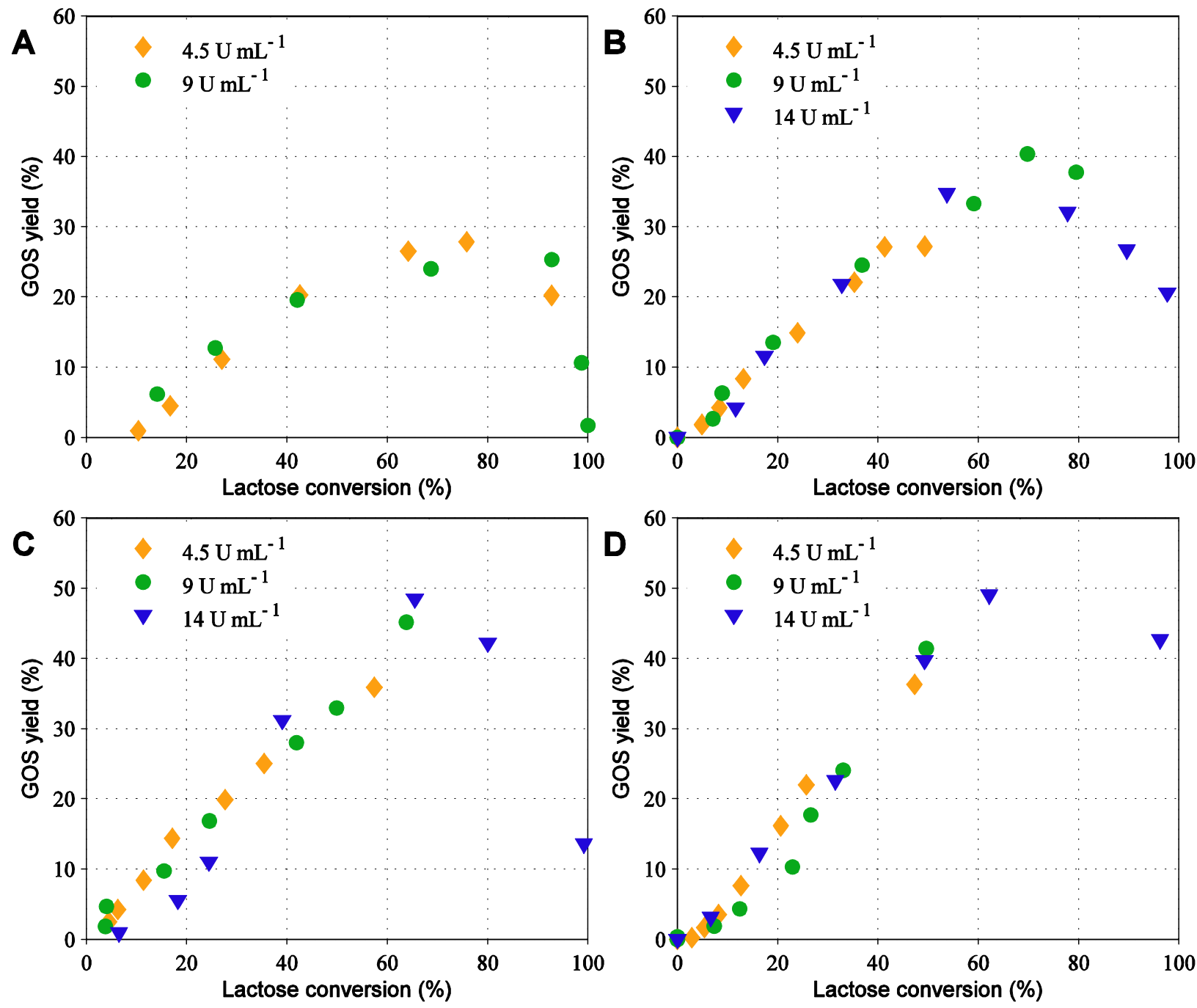

Figure 5: Effect of initial lactose concentration (A: $25 \mathrm{~g} \mathrm{~L}^{-1}, \mathrm{~B}: 50 \mathrm{~g} \mathrm{~L}^{-1}, \mathrm{C}: 100 \mathrm{~g} \mathrm{~L}^{-1}, \mathrm{D}: 150 \mathrm{~g} \mathrm{~L}^{-1}$ ) and enzyme concentration due to GOS yield versus lactose conversion $\left(\mathrm{pH} 7.4,40^{\circ} \mathrm{C}\right)$, data points present samples taken in an interval of 0/0.25/0.5/1/2/4/6/24 hours (order with rising lactose conversion)

For further detailed determination of the reaction mechanism of the enzyme the following main operation conditions were chosen: $\mathrm{pH} 7.4, \mathrm{~T}: 40{ }^{\circ} \mathrm{C}$, ILC: $100 \mathrm{~g} \mathrm{~L}^{-1}, m_{\text {Cat }}: 4.5 \mathrm{U} \mathrm{mL}^{-1}$.

\section{Reaction Network Analysis}

Besides temperature, $\mathrm{pH}$ value and enzyme/substrate ratio the reaction or residence time is one of the most important process parameters with respect to industrial operations. Figure 6 
shows the development of GOS formation and lactose consumption till six hours and for 24 hours fermentation at various enzyme concentrations $\left(4.5 / 9 / 14 \mathrm{U} \mathrm{mL}^{-1}\right)$. The graphs of GOS formation reveal in comparison to the enzyme concentration the same transgalactosylation activity for the first hour. After two hours the transgalactosylation rate is increasing with the amount of enzyme. Subsequently the rate of the $14 \mathrm{U} \mathrm{mL}^{-1}$ sample increases markedly until it reaches after four hours a maximum. Afterwards the GOS concentration is decreasing with increasing monosaccharide formation (data not shown) due to a preferential hydrolysis activity which indicates a change in the reaction network as discussed before. The batches with lower enzyme concentration have a considerable moderate transgalactosylation rate. These differences illustrate the importance of the knowledge about the change of rates over time to understand the reaction mechanism and to achieve highest GOS concentration in product. Furthermore, it allows an interpretation of the enzyme kinetics and will studied in detail by static and dynamic inhibition experiments, respectively.

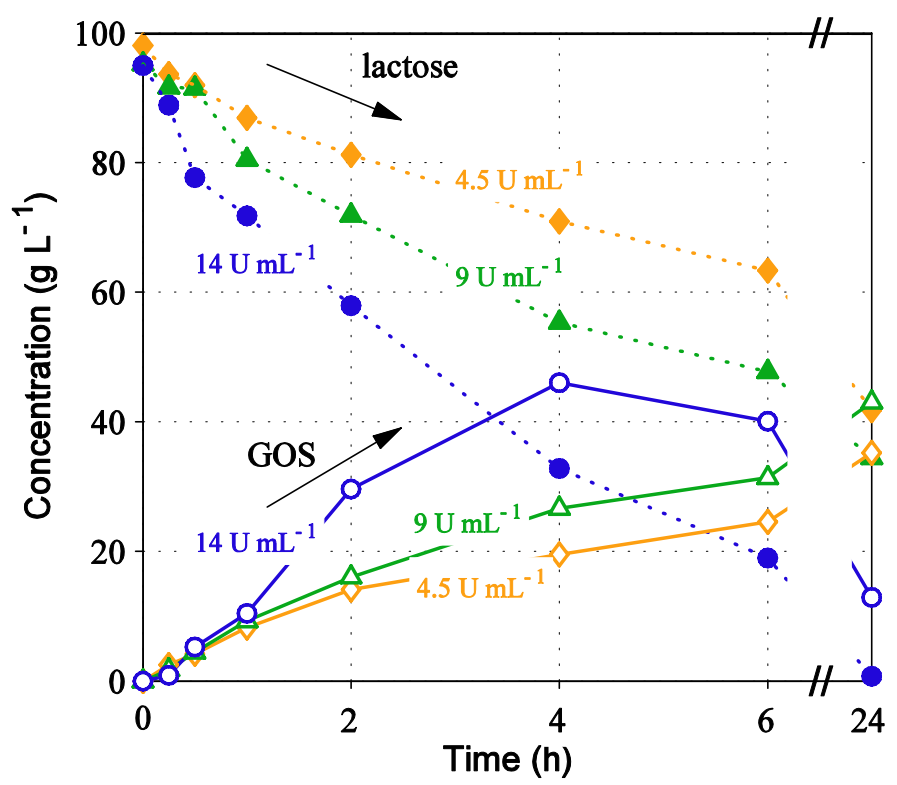

Figure 6: Development of lactose reduction (dotted lines/open symbols) and GOS formation (solid lines/filled symbols) versus time in relation to enzyme concentration (ILC: $100 \mathrm{~g} \mathrm{~L}^{-1}, \mathrm{~T}: 40{ }^{\circ} \mathrm{C}$, $\mathrm{pH} 7.4)$

\subsection{Static Inhibition Experiments}

In fig. 7 the temporal concentration courses of all species are depicted. As already mentioned in fig. 1 lactose is converted to the desired product GOS by the transgalactosylation reaction as well as the side products glucose and galactose are formed. To study the reaction network, 
reversibility and possible inhibiting effects of the side products instructive perturbation experiments are illustrated in the following.

The determination of the inhibition effects of glucose and galactose was proved with an additional dosing of those monosaccharides separately in a concentration of $10 \mathrm{~g} \mathrm{~L}^{-1}$ or $50 \mathrm{~g}$ $\mathrm{L}^{-1}$ to the initial lactose concentration of $100 \mathrm{~g} \mathrm{~L}^{-1}$ before starting the fermentation process. The experimental results offer the inhibition effects of galactose in comparison to the GOS synthesis without perturbation (dotted lines). With additional $10 \mathrm{~g} \mathrm{~L}^{-1}$ galactose the GOS concentration curve evinces a significant $21 \%$ lower formation rate. With additional $50 \mathrm{~g} \mathrm{~L}^{-1}$ the GOS formation comes to a complete standstill. The same behaviour can be observed with additional $10 \mathrm{~g} \mathrm{~L}^{-1}$ and $50 \mathrm{~g} \mathrm{~L}^{-1}$ glucose (data not shown). Thus, the additional feeding of galactose and glucose reveals an inhibiting effect in the reaction mechanism and has to be included in the reaction network and catalytic cycle (chapter 5.3, fig. 9), respectively.
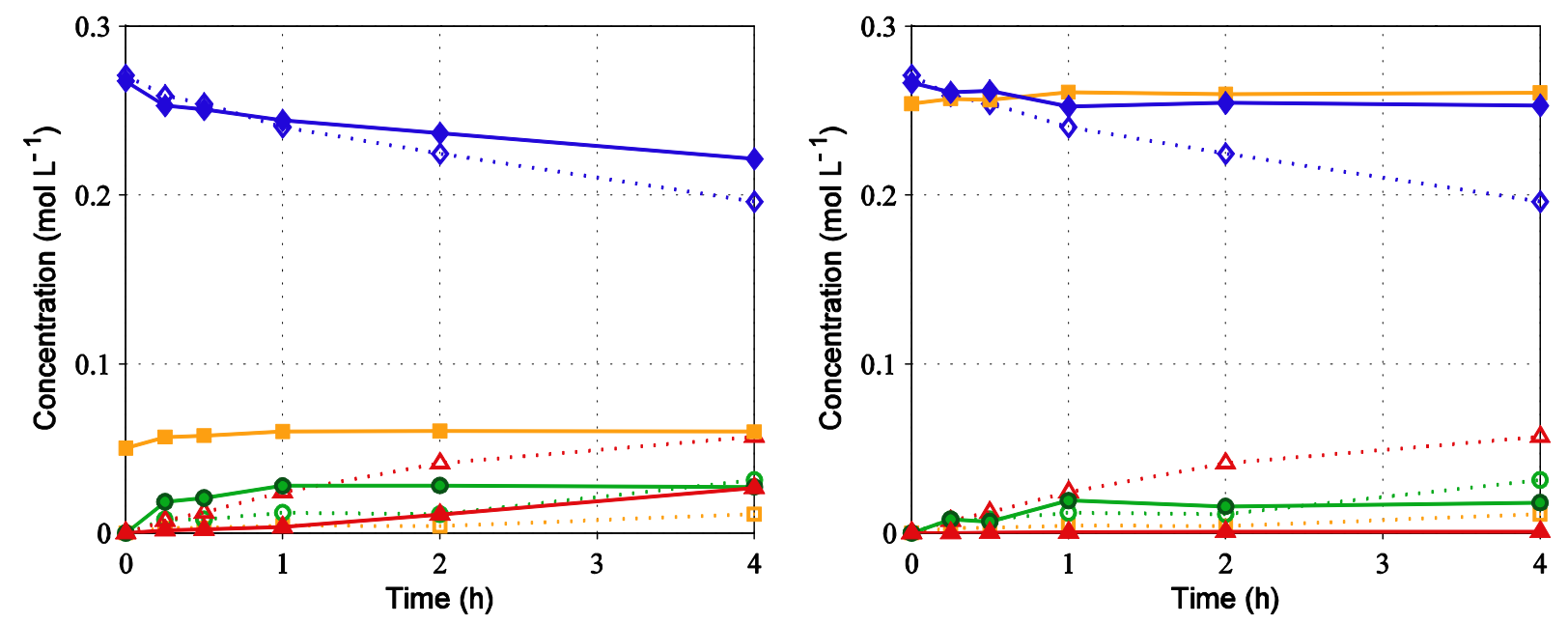

Figure 7: $\quad$ Time course of product (gal $\square$, glu $\bullet$, GOS $\boldsymbol{\Delta}$ ) and substrate (lac $\bullet$ ) during GOS synthesis over four hours reaction time with additional $10 \mathrm{~g} \mathrm{~L}^{-1}$ (left side) and $50 \mathrm{~g} \mathrm{~L}^{-1}$ (right side) galactose to $100 \mathrm{~g} \mathrm{~L}^{-1}$ ILC (lines/filled symbols), $\mathrm{pH} 7.4$, T: $40{ }^{\circ} \mathrm{C}, m_{\text {Cat }}: 4.5 \mathrm{U} \mathrm{mL}^{-1}$, dotted lines/empty symbols: reference sample without perturbation

\subsection{Dynamic Inhibition Experiments}

Dynamic experiments characterized by temporal perturbation e. g. in concentration give in advantage to grant the enzyme a certain time of activation, before a shift of equilibration is caused. Rates will change by perturbations providing instructive information for parameter estimation and the number of kinetic experiments can be reduced. For dynamic inhibition experiments a perturbation was performed with $10 \mathrm{~g} \mathrm{~L}^{-1}$ or $50 \mathrm{~g} \mathrm{~L}^{-1}$ galactose (not depicted) or glucose into a running enzymatic reaction process (30 min after fermentation start) in order to obtain sensitive kinetic parameters. Figure 8 depicts the resulting concentrations of all 
species in GOS mixture due to dynamic glucose perturbation. Due to perturbation with $10 \mathrm{~g} \mathrm{~L}^{-1}$ glucose $30 \%$ less GOS yield is reached after $24 \mathrm{~h}$ compared to the reference reaction. While the perturbation with $50 \mathrm{~g} \mathrm{~L}^{-1}$ induced a complete inhibition of GOS formation which confirms the observations made at the static inhibition experiments. The results also coincides with those of literature, where for many $\beta$-galactosidases of divergent species galactose and/or to a lesser degree glucose are well known inhibitors of lactose hydrolysis (Boon et al., 2000; Neri et al., 2009; Vera et al., 2011). This perturbation experiments reveal a deeper insight into the kinetic mechanism and kinetic rates. The data allow to perform a sensitivity analysis by the subset selection method and to extract sensitive kinetic parameters only. Thus, a model reduction of the derived mechanistic models on the basis of a catalytic cycle is possible containing sensitive parameters only as discussed below.
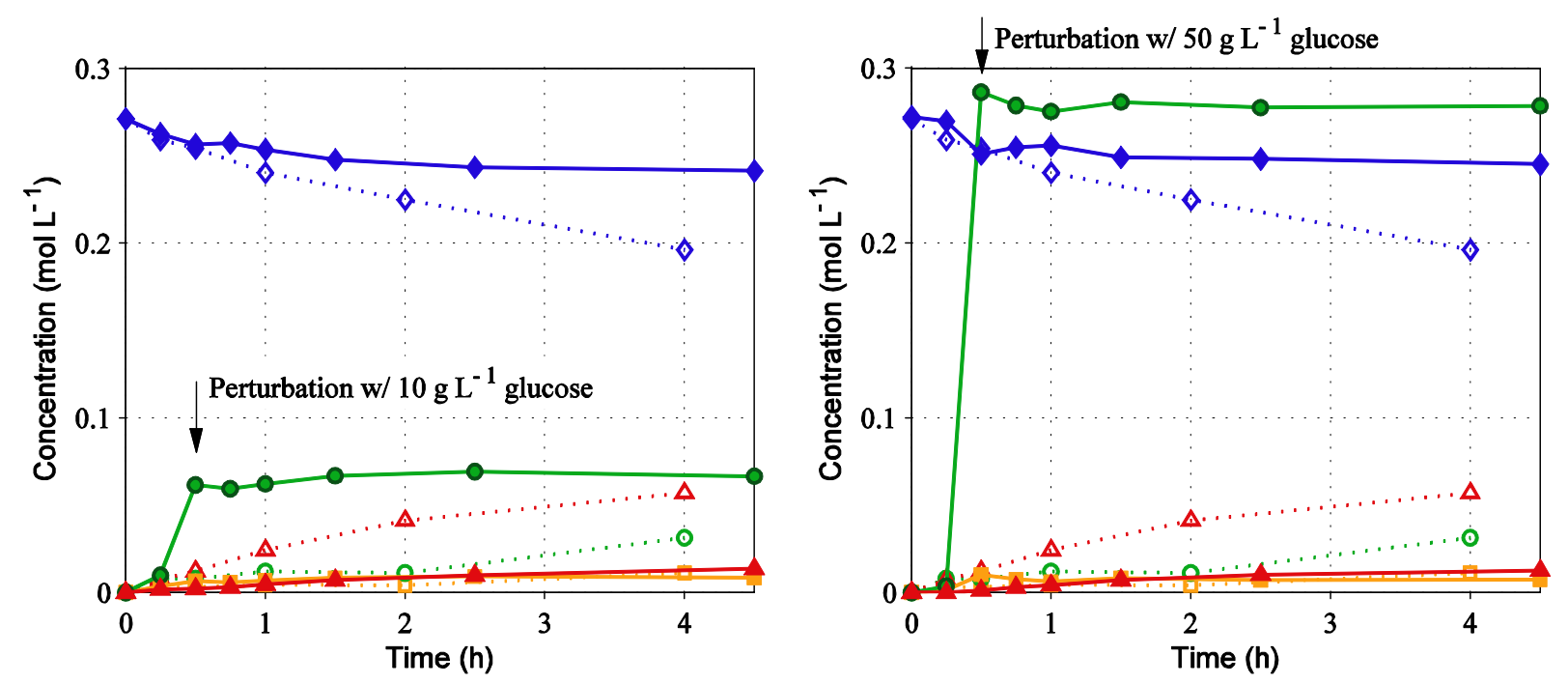

Figure 8: Time course of product (gal $\square$, glu $\bullet$, GOS $\boldsymbol{\Delta}$ ) and substrate (lac $\bullet$ ) during GOS synthesis over four hours reaction time with a $10 \mathrm{~g} \mathrm{~L}^{-1}$ (left side) and $50 \mathrm{~g} \mathrm{~L}^{-1}$ (right side) glucose perturbation after 30 minutes (solid lines), ILC: $100 \mathrm{~g} \mathrm{~L}^{-1}, \mathrm{pH} 7.4, \mathrm{~T}: 40{ }^{\circ} \mathrm{C}, m_{\mathrm{Cat}}: 4.5 \mathrm{U} \mathrm{mL}^{-1}$, dotted lines: reference sample without perturbation

\subsection{Postulated catalytic cycle for the enzyme $\beta$-galactosidase}

As conclusion of the experimental studies as well the inhibition experiments in combination with proven state of the art for $\beta$-galactosidase from E. coli for GOS formation from lactose the following extended catalytic cycle can be postulated (see fig. 9). Starting on top of the cycle the enzyme (E) in resting state reacts with the substrate lactose to an enzyme-lactose complex $\left(\omega_{1}\right)$. In a subsequent step $\left(\omega_{2}\right)$ lactose is cut into its monomers building an enzymegalactose-glucose-complex from which the glucose gets hydrolysed in step $\omega_{3}$, remaining an enzyme-galactose-complex in cycle. Due to the repeatedly described equilibration limited 
reaction mechanism (Meyer et al., 2015; Palai and Bhattacharya, 2013; Palai et al., 2015) the complex can either react with water and form through hydrolysis galactose and unbound enzyme $\left(\omega_{6}\right)$ or react with a galactosyl acceptor to an enzyme-galacto-oligosaccharide complex $\left(\omega_{4}\right)$. Possible galactosyl acceptors can be all in solution present saccharides like glucose, galactose, lactose and GOS DP > 2. In a consecutive step $\left(\omega_{5}\right)$ the galactooligosaccharide is released from the enzyme. Thus, the resting state $\mathrm{E}$ is established and the cycle starts again. The static inhibition experiments with feed mixtures (lactose, glucose and galactose) and the dynamic perturbations with glucose $\left(K_{7}\right)$ and/or galactose $\left(K_{8}\right)$ revealed an inhibiting effect on the active catalyst/enzyme (E). Thus, the reaction rates are reduced which has to be included in the mechanistic kinetic models as well.

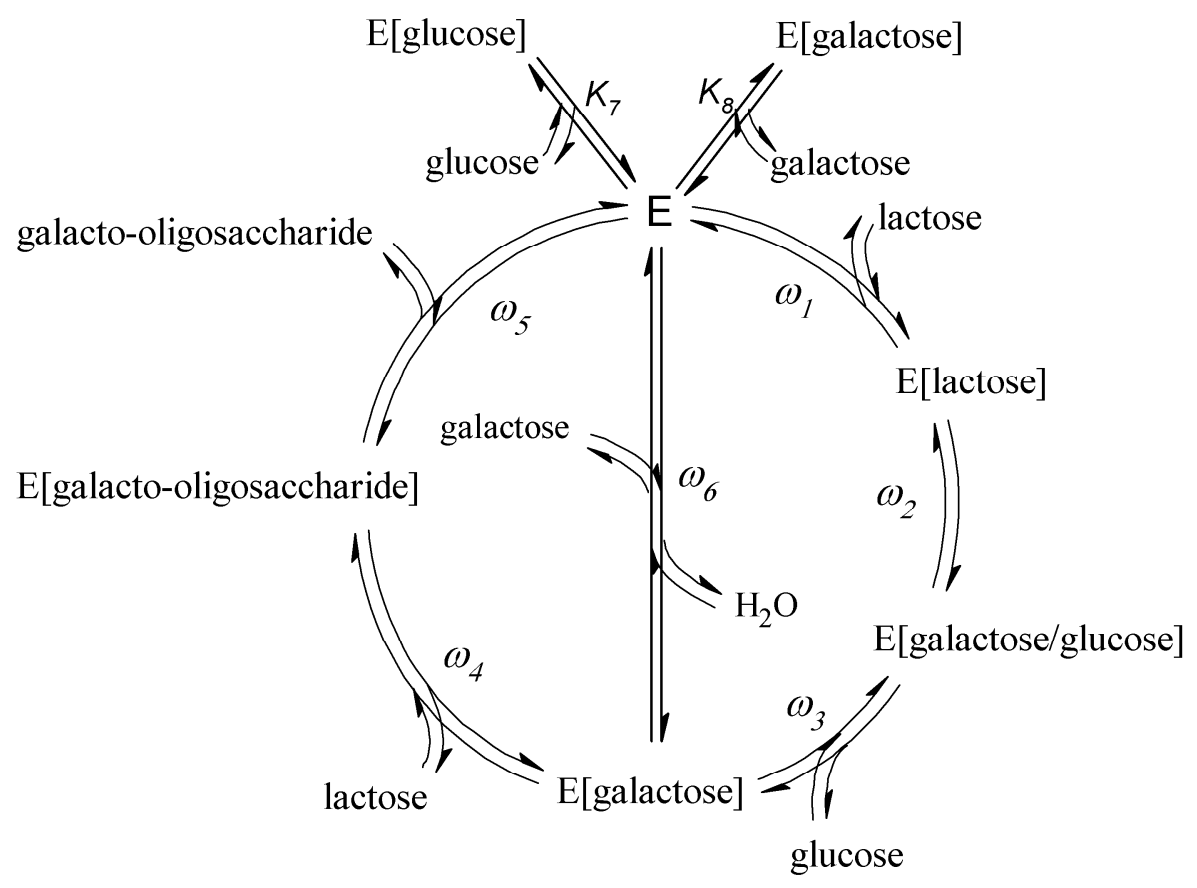

Figure 9: Postulated catalytic cycle of the lactose conversion to galacto-oligosaccharide including formation of side products and inhibition effects of glucose and galactose

As the enzyme powder got immediately dissolved in the reaction medium, it can be termed to be a homogeneous reaction with no mass transfer limitations. Furthermore, in preliminary investigations on a varying stirrer speed no impact on the mass transfer was found (data not shown). 


\section{Kinetic Modelling}

\subsection{Development of mechanistic kinetic rate models}

Based on the kinetic analysis and the developed catalytic cycle (see figs. 2 and 9) mechanistic kinetic rate models using Christiansen methodology can be derived. The derivation of the Christiansen matrix of a three-step catalytic cycle is suggested in the appendix of this manuscript. In this way, the Christiansen matrix of a four-step catalytic cycle can be determined as well.

\section{Lactose decomposition to galactose and glucose}

First the lactose decomposition to galactose and glucose including the cycle steps $\omega_{1}, \omega_{2}, \omega_{3}$ and $\omega_{6}$ is determined. Additionally, to the involved steps, the inhibition of the enzyme concentration in resting state $(\mathrm{E})$ by glucose $\left(K_{7}\right)$ and galactose $\left(K_{8}\right)$ is considered. The enzyme concentration is included in the partial mass balance in eq. 3 as mass enzyme used per batch volume. Thus, the reaction rate of the lactose decomposition can be determined according to eq. 1 and results in eq. 6 .

$$
r=\frac{\left(\omega_{1}^{+} \omega_{2}^{+} \omega_{3}^{+} \omega_{6}^{+}-\omega_{1}^{-} \omega_{2}^{-} \omega_{3}^{-} \omega_{6}^{-}\right)}{\left(\begin{array}{c}
\omega_{2}^{+} \omega_{3}^{+} \omega_{6}^{+}+\omega_{1}^{-} \omega_{3}^{+} \omega_{6}^{+}+\omega_{1}^{-} \omega_{2}^{-} \omega_{6}^{+}+\omega_{1}^{-} \omega_{2}^{-} \omega_{3}^{-} \\
+\omega_{1}^{+} \omega_{3}^{+} \omega_{6}^{+}+\omega_{1}^{+} \omega_{2}^{-} \omega_{6}^{+}+\omega_{1}^{+} \omega_{2}^{-} \omega_{3}^{-}+\omega_{2}^{-} \omega_{3}^{-} \omega_{6}^{-} \\
+\omega_{1}^{+} \omega_{2}^{+} \omega_{6}^{+}+\omega_{1}^{+} \omega_{2}^{+} \omega_{3}^{-}+\omega_{2}^{+} \omega_{3}^{-} \omega_{6}^{-}+\omega_{1}^{-} \omega_{3}^{-} \omega_{6}^{-} \\
+\omega_{1}^{+} \omega_{2}^{+} \omega_{3}^{+}+\omega_{2}^{+} \omega_{3}^{+} \omega_{6}^{-}+\omega_{1}^{-} \omega_{3}^{+} \omega_{6}^{-}+\omega_{1}^{-} \omega_{2}^{+} \omega_{6}^{-}
\end{array}\right)\left(\begin{array}{c}
\omega_{6}^{-} \\
+\omega_{1}^{-} \omega_{3}^{+} \omega_{6}^{+} \\
+\omega_{1}^{-} \omega_{2}^{-} \omega_{6}^{+} \\
+\omega_{1}^{-} \omega_{2}^{-} \omega_{3}^{-}
\end{array}\right)\left(\begin{array}{c}
K_{7} c_{\text {glu }} \\
+K_{8} c_{\text {gal }}
\end{array}\right)}
$$

Assuming that the glucose elimination (step 3$)$ is irreversible $\left(\omega_{3}{ }^{-}=0\right)$ eq. 6 can be simplified to:

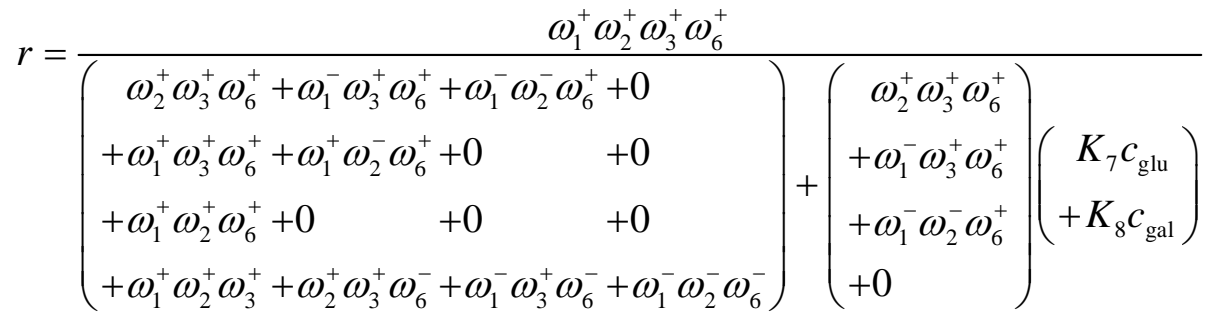

By substitution of the single step frequencies $\omega_{\text {jstep }}$ by the step kinetic constants $k$ (i.e. $\omega_{1}^{+}=$ $\left.k_{1}^{+} \cdot c_{\text {lac }}\right)$, eq. 7 can be written as: 


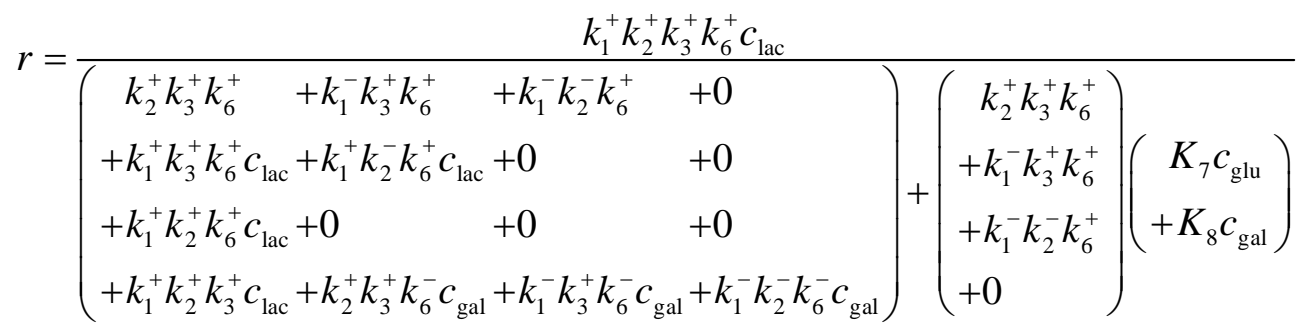

After final rearrangements eq. 8 follows eq. 9:

$$
r=\frac{k_{1} c_{\mathrm{lac}}}{\left(K_{11} c_{\mathrm{lac}}+\left(1+K_{12}\right)\left(1+c_{\mathrm{gal}} / K_{6}+K_{7} c_{\mathrm{glu}}+K_{8} c_{\mathrm{gal}}\right)\right)}
$$

The consolidated inhibition constants $K_{11}$ and $K_{12}$ correspond to the eqs. 10 and 11, respectively. Based on these assumptions the number of unknown parameters can be reduced from 14 to 6.

$$
K_{11}=\frac{k_{1}^{+}}{k_{2}^{+}}+\frac{k_{1}^{+}}{k_{3}^{+} K_{2}}+\frac{k_{1}^{+}}{k_{3}^{+}}+\frac{k_{1}^{+}}{k_{6}^{+}} \quad \text { (10) } \quad \text { and } \quad K_{12}=\frac{k_{1}^{-}}{k_{2}^{+}}+\frac{k_{1}^{-}}{k_{3}^{+} K_{2}}
$$

\section{GOS formation}

The determination of the GOS polymerization from, the catalytic cycle steps from $\omega_{4}$ to $\omega_{6}$, are considered (see fig. 9). Additionally, the inhibition behaviour of glucose $\left(K_{7}\right)$ and galactose $\left(K_{8}\right)$ at the enzyme in resting state are included as well (see eq. 12). As galactosyl acceptor lactose is assumed.

$$
r=\frac{\left(\omega_{6}^{-} \omega_{4}^{+} \omega_{5}^{+}-\omega_{6}^{+} \omega_{4}^{-} \omega_{5}^{-}\right)}{\left(\begin{array}{c}
\omega_{4}^{+} \omega_{5}^{+}+\omega_{6}^{+} \omega_{5}^{+}+\omega_{6}^{+} \omega_{4}^{-} \\
+\omega_{6}^{-} \omega_{5}^{+}+\omega_{6}^{-} \omega_{4}^{-}+\omega_{4}^{-} \omega_{5}^{-} \\
+\omega_{6}^{-} \omega_{4}^{+}+\omega_{4}^{+} \omega_{5}^{-}+\omega_{6}^{+} \omega_{5}^{-}
\end{array}\right)+\left(\begin{array}{c}
\omega_{4}^{+} \omega_{5}^{+} \\
+\omega_{6}^{+} \omega_{5}^{+} \\
+\omega_{6}^{+} \omega_{4}^{-}
\end{array}\right)\left(\begin{array}{c}
K_{7} c_{\text {glu }} \\
+K_{8} c_{\text {gal }}
\end{array}\right)}
$$

Assuming that the polymerization step is rate-determining $\left(\omega_{4} \ll \omega_{5}\right.$ and $\left.\omega_{4} \ll \omega_{6}\right)$ eq. 12 can be reduced to eq. 13 .

$$
r=\frac{\left(\omega_{6}^{-} \omega_{4}^{+} \omega_{5}^{+}-\omega_{6}^{+} \omega_{4}^{-} \omega_{5}^{-}\right)}{\left(\omega_{6}^{-} \omega_{5}^{+}+\omega_{6}^{+} \omega_{5}^{-}+\omega_{6}^{+} \omega_{5}^{+}\left(1+K_{7} c_{\text {glu }}+K_{8} c_{\text {gal }}\right)\right)}
$$


By inserting the single step constants (i.e. $\omega_{6}{ }^{-}=k_{6}{ }^{-} \cdot c_{\text {gal }}$ ) and definition of the equilibrium reaction constant $K_{\mathrm{p}}$ (Helfferich, 2004) the mechanistic reaction rate approach of the GOS polymerization follows eq. 14 .

$$
r=\frac{k_{2}\left(c_{\mathrm{gal}} c_{\mathrm{lac}}-c_{\mathrm{GOS}} / K_{\mathrm{p}}\right)}{\left(c_{\mathrm{gal}}+K_{6}\left(1+c_{\mathrm{GOS}} / K_{5}+K_{7} c_{\mathrm{glu}}+K_{8} c_{\mathrm{gal}}\right)\right)}
$$

On closer inspection of the derived reaction rate approaches (eqs. 9 and 14) the single step equilibrium constants $K_{6-8}$ are part of both. Correspondingly the parameter estimation of the rate laws has to be simultaneously at the available experimental data. If only $\omega_{1}$ is reversible and $\omega_{2}, \omega_{3}$ and $\omega_{6}$ are irreversible, no rate-determining and/or no product inhibition proceeds and the Michaelis-Menten kinetic can be derived from this more general approach in eq. 14 (Helfferich, 2004).

The quantification of the temperature effect in the kinetic constants and inhibition factors can be described using a typical Arrhenius approach (see eq. 15).

$$
k_{\mathrm{j}}(T)=k_{\infty, \mathrm{j}} \exp \left(\frac{-E_{\mathrm{A}, \mathrm{j}}}{\tilde{R} \cdot T}\right)
$$

\subsection{Estimated kinetic data}

The estimation of the kinetic constants as well as the inhibition parameters (see eqs. 9 and 14) occurred on isothermal batch experimental data with different initial concentrations of lactose, glucose, galactose, GOS and enzyme. Except of the temperature dependent kinetic constants all equilibrium parameters were estimated independent from temperature to avoid ill-posed parameter optimization problems. The resulting set of parameters are summarized in the table 1 and 2. Based on the temperature dependent rate constant pre-factor $k_{\infty}$ and activation energy $E_{\mathrm{A}}$ in the Arrhenius approach (see. eq. 15) could be estimated in eq. 8 with $k_{\infty, 1}=1.428 \cdot 10^{+10} \mathrm{~s}^{-1}, E_{\mathrm{A}, 1}=50.758 \mathrm{~kJ} \cdot \mathrm{mol}^{-1}$ and in eq. 14 with $k_{\infty, 2}=1.472 \cdot 10^{+9} \mathrm{~s}^{-1}, E_{\mathrm{A}, 2}=52.901$ $\mathrm{kJ} \cdot \mathrm{mol}^{-1}$ in a temperature range of $20-40^{\circ} \mathrm{C}$ excluding deactivation effects of the enzyme. The performed subset selection revealed for $K_{5}$ an infinite number for all temperatures investigated. Thus, the term $c_{\mathrm{GOS}} / K_{5}$ in eq. 14 becomes to be zero and can be excluded for the experimental conditions studied. Outside this range the shown kinetic parameters are not valid.

The kinetic analysis is focused on the first four experimental hours. Accordingly, kinetic controlled experimental data are ensured. For the determination of the equilibrium reaction 
constant $K_{\mathrm{p}}$ of the GOS polymerization using single component Gibbs energies of formation experimental or literature data are not available. Thus, an infinite $K_{\mathrm{p}}$ value is assumed reducing eq. 14 in addition.

Table 1: Temperature dependent estimated kinetic parameters for several reaction temperatures (see also eqs. 9 and 14 )

\begin{tabular}{lccccc}
\hline Parameter & $20{ }^{\circ} \mathrm{C}$ & $30{ }^{\circ} \mathrm{C}$ & $40{ }^{\circ} \mathrm{C}$ & $50{ }^{\circ} \mathrm{C}$ & $60{ }^{\circ} \mathrm{C}$ \\
\hline$k_{1}, \mathrm{~s}^{-1}$ & $3.976 \cdot 10^{-1}$ & $9.344 \cdot 10^{-1}$ & 1.408 & 2.320 & $4.610 \cdot 10^{-1}$ \\
$k_{2}, \mathrm{~s}^{-1}$ & 5.682 & 36.231 & 48.780 & 40.992 & 1.750 \\
\hline
\end{tabular}

Table 2: $\quad$ Temperature independent estimated kinetic parameters (see also eqs. 9 and 14)

\begin{tabular}{ll|ll}
\hline Parameter & Value & Parameter & Value \\
\hline$K_{11}, \mathrm{~L} \cdot \mathrm{mol}^{-1}$ & 0 & $K_{12},-$ & $4.533 \cdot 10^{+3}$ \\
$K_{6}, \mathrm{~mol} \cdot \mathrm{L}^{-1}$ & 1 & $K_{7}, \mathrm{~L}^{-\mathrm{mol}^{-1}}$ & $1.339 \cdot 10^{+3}$ \\
$K_{8}, \mathrm{~L} \cdot \mathrm{mol}^{-1}$ & $2.868 \cdot 10^{+4}$ & & \\
\hline
\end{tabular}

\subsection{Validation of reaction kinetics}

The validation of the reaction kinetics for different initial catalyst/enzyme and lactose concentrations is shown in fig. 10 for the reactant lactose and all products. The remaining reaction properties are considered for $T=40^{\circ} \mathrm{C}$ and $\mathrm{pH}=7.4$. As aforementioned in section five the transgalactosylation rate is increasing with the amount of enzyme. The model prediction for lactose is in a good agreement with the experiment for all enzyme and lactose concentrations studied. Accordingly, the lactose decrease and increase of glucose, galactose and GOS is accelerated. This behaviour is reflected by the reactor and kinetic model as well in fig. 10 A. Furthermore, the intermediate product galactose is described by the kinetic model very well and allows a process modelling and model based optimization. However, the ratio of the formed glucose and GOS concentration especially for the higher enzyme concentrations and lactose conversion fits not well. Based on the postulated reaction network structure the formed glucose amount correlates to the maximal formed GOS concentration. Accordingly, a higher GOS amount compared to glucose concentration cannot be sufficiently reflected by the kinetic model. This phenomenon was observed for different initial lactose concentrations as well (see fig. 10 B). Correspondingly, the GOS concentration is underestimated for the increased lactose initial concentration. 
Thus, the reaction network might be changed as already discussed in chapter 4.2 , fig. 5 . Therefore, e.g. an additional reaction has to be taken into account. Furthermore, lactose was assumed as galactosyl acceptor in fig. 9. If other species react as a galactosyl acceptor different rates or rate constants will occur in eq. 14. In correlation to it, as it has been described in chapter 4.2 , the hydrolysis to transgalactosylation ratio can be significantly shifted by the change of the enzyme or lactose concentration, causing a differing formation of GOS species. When the transgalactosylation activity is increased by such a parameter, the probability rises for higher GOS species to serve as galactosyl acceptor in the GOS formation process. In closing, a modification in the enzyme specificity can explain the deficit in the kinetic modelling caused by an altered enzyme to substrate ratio like objected in fig. $10 \mathrm{~A}$ and B. However, the in-situ analysis of intermediate species other than lactose is difficult and should be handled as option for subsequent work.
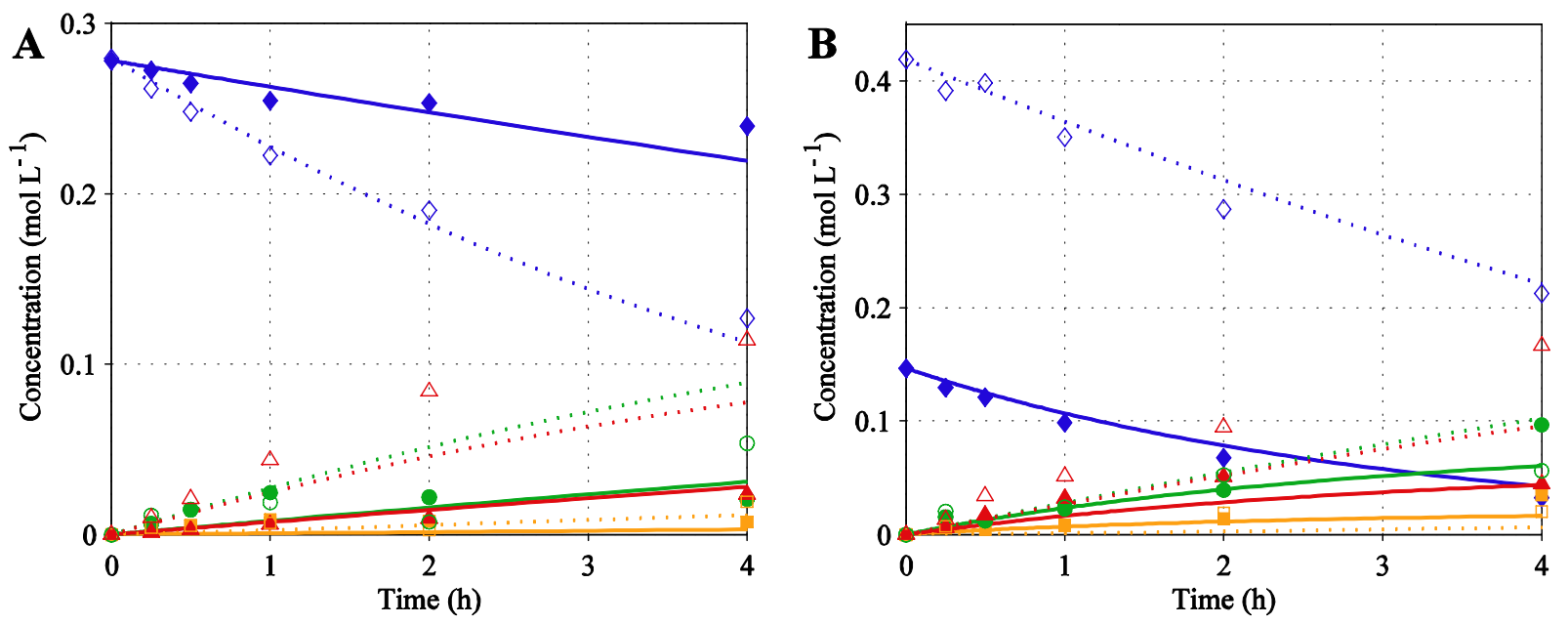

Figure 10: Concentration profiles of lac $\diamond$, gal $\square$, glu $\bullet$ and GOS $\boldsymbol{\Delta}$ over time for (A) two different catalyst masses: $m_{\text {cat }}=4.5 \mathrm{U} \mathrm{mL}^{-1}$ with solid lines (modelled) and open symbols (experimental) and $m_{\text {cat }}=$ $14 \mathrm{U} \mathrm{mL}^{-1}$ with dotted lines (modelled) and open symbols (experimental) and (B) two different initial lactose concentrations: $c_{\text {lac }}=50 \mathrm{~g} \mathrm{~L}^{-1}$ with solid lines (modelled) and open symbols (experimental) and $c_{\mathrm{lac}}=140 \mathrm{~g} \mathrm{~L}^{-1}$ with dotted lines (modelled) and open symbols (experimental)

As aforementioned the transgalactosylation rate can be inhibited by glucose and galactose (see fig. 7 and fig. 8). For the corresponding quantification of these kinetic effects the inhibition parameters $K_{7}$ and $K_{8}$ (see eqs. 9 and 14) are available and were parameterized based on the static perturbation experiments (see tab. 2). A comparison of experimental and the model based simulations for the static perturbation with glucose and galactose is given for the reactant lactose and all products at a lactose feed of $100 \mathrm{~g} \mathrm{~L}^{-1}$ and a low enzyme amount of $4.5 \mathrm{U} \mathrm{mL}^{-1}$ in fig. 11. 

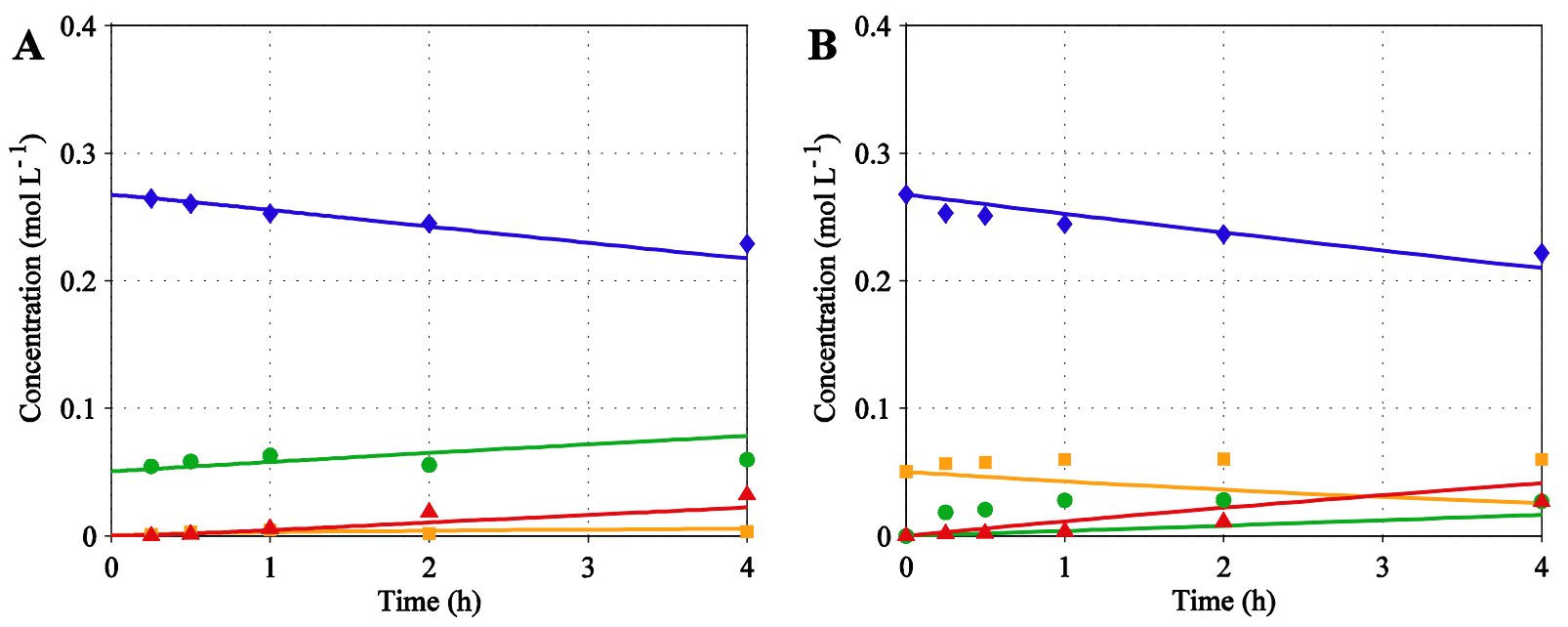

Figure 11: Concentration profiles for lac $\bullet$, gal $₫$, glu $\bullet$, GOS $\Delta$ over time for (A) static glucose perturbation $\left(c_{\text {glu }}{ }^{0}=0.50 \mathrm{~mol} \cdot \mathrm{L}^{-1}\right)$ and $(\mathbf{B})$ static galactose perturbation $\left(c_{\text {gal }}{ }^{0}=0.50 \mathrm{~mol} \cdot \mathrm{L}^{-1}\right)$, symbols are experimental data and lines are modelled data, ILC $=100 \mathrm{~g} \mathrm{~L}^{-1}, \mathrm{pH} \mathrm{7.4}, \mathrm{T}=40^{\circ} \mathrm{C}, m_{\mathrm{Cat}}=$ $4.5 \mathrm{U} \mathrm{mL}^{-1}$

Accordingly, the model based description of these data in the perturbation with glucose (fig. $11 \mathrm{~A})$ is very well. The perturbation with galactose in fig $11 \mathrm{~B}$ offers a good description of lactose. Thus, there is a good mathematical modelling of the lactose hydrolysis described by eq. 9. High concentrations of galactose as adjusted artificially by the perturbation with galactose, which will cannot occur in the transgalactosylation to GOS, are not sufficiently described. Here an overestimation of the inhibiting effect of galactose is predicted by the derived mathematical model. Nevertheless, the remaining experimental concentration profiles are in good agreement with the modelled data.

Finally, it can be stated that the large amount of experimental and calculated results were found to be in good agreement with respect to the individual sub-networks and the total network for the temperature, $\mathrm{pH}$-value, lactose and enzyme concentration range covered.

\section{Conclusion}

The reaction mechanism was studied of GOS formation from lactose as substrate with $\beta$ galactosidase from E. coli. Systematic experiments were conducted to determine optimized reaction conditions with respect to temperature, $\mathrm{pH}$ value, enzyme concentration and initial lactose concentration. Detailed kinetic studies were performed to understand the reaction network and to identify most sensitive parameters. The influence of the substrate and in particular inhibition effects of the side products galactose and glucose were determined with 
instructive static and dynamic perturbations, revealing a mutual suppression of the reaction. While models of literature describe the GOS formation with separate proceeding stages, this study provides a holistic description of considering inhibiting effects by glucose and galactose. Based on the identified reaction network a catalytic cycle was postulated, including lactose decomposition (hydrolysis), GOS formation (transgalactosylation) and product inhibition. The methodology from Christiansen considering elementary steps in the catalytic cycle without rate-determining assumptions was successfully applied to derive mechanistic reversible kinetic models for the GOS synthesis. In relation to experimental data a sensitivity analysis by the subset selection method, to estimate sensitive parameters only, was performed providing reduced models for lactose degradation as well as for the GOS formation. The subsequent evaluation of the kinetic models revealed a good correlation with the experimental data and allowed a good mathematical description in a broad range of operating conditions. The derived kinetic models and parameters can be helpful for design and model based optimization of bio reactors and process intensification.

\section{Acknowledgements}

The authors gratefully acknowledge the funding by the German Federal Ministry of Education and Research (BMBF) within the framework of the FHprofUnt 2014 (project number: 03FH017PX4). 


\section{Latin letters}

\begin{tabular}{|c|c|c|}
\hline$c_{\mathrm{i}}$ & $\mathrm{mol}^{\circ} \mathrm{L}^{-1}$ & concentration of component $\mathrm{i}$ \\
\hline$E_{\mathrm{A}}$ & $\mathrm{kJ} \mathrm{mol}^{-1}$ & activation energy \\
\hline$k$ & $\mathrm{~s}^{-1}$ & reaction rate constant \\
\hline $\mathrm{k}_{\infty}$ & $\mathrm{s}^{-1}$ & prefactor \\
\hline$K$ & [varies] & lumped inhibition coefficient in rate approaches \\
\hline$K_{\mathrm{p}}$ & $\mathrm{mol}^{-1} \cdot \mathrm{L}$ & equilibrium constant \\
\hline$m_{\text {cat }}$ & $\mathrm{kg}$ & mass of catalyst/enzyme \\
\hline$M$ & $\mathrm{~g} \mathrm{~mol}^{-1}$ & molar mass \\
\hline$n$ & mol & amount of substance \\
\hline$O F$ & - & objective function \\
\hline$R$ & $\mathrm{~J} \cdot(\mathrm{mol} \cdot \mathrm{K})^{-1}$ & universal gas constant \\
\hline$r$ & $\operatorname{mol}\left(\mathrm{kg}_{\mathrm{cat}} \cdot \mathrm{s}\right)^{-1}$ & reaction rate \\
\hline$t$ & $s$ & time \\
\hline$T$ & $\mathrm{~K}$ & temperature \\
\hline$V_{\mathrm{R}}$ & $\mathrm{m}^{3}$ & reaction volume \\
\hline
\end{tabular}

\section{Greek letters}

$\begin{array}{lll}\Theta_{\mathrm{opt}} & - & \text { optimization parameter vector } \\ \omega & - & \text { cycle step frequencies } \\ \Omega & - & \text { Christiansen matrix } \\ \nu_{\mathrm{ij}} & - & \text { stoichiometric coefficient of component } \mathrm{i} \text { in rate } \mathrm{j}\end{array}$

\section{Subscripts}

$\begin{array}{ll}\text { cat } & \text { catalyst/enzyme } \\ \mathrm{dos} & \text { dosing } \\ \exp & \text { experimental } \\ \mathrm{i} & \text { index of component } \\ \mathrm{j} & \text { index of reaction } \\ \text { mod } & \text { modelled } \\ \text { opt } & \text { optimal } \\ \text { tot } & \text { total }\end{array}$

\section{Superscripts}
$N_{\mathrm{c}}$
$N_{\text {obs }}$
$N_{\mathrm{R}}$
$N_{\text {step }}$
0

\section{Abbreviation}

$\beta$-gal
DP
E
glu

number of components

number of observations

number of reactions

number of elementary steps in a catalytic cycle initial 


\section{Appendix}

\section{Derivation of the Christiansen Matrix}

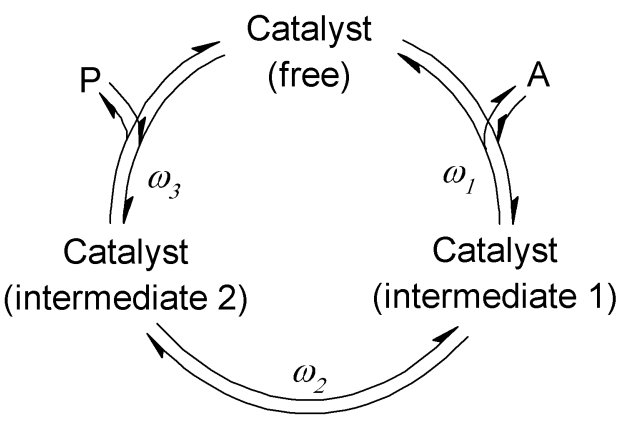

Figure A1: General three-step catalytic cycle

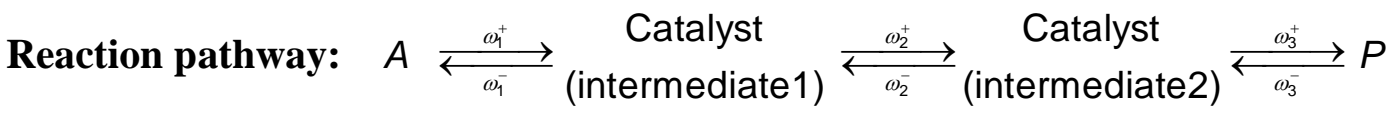

Set of rate equations:

$$
\begin{aligned}
& r_{\mathrm{P}}=\omega_{3}^{+} c_{\mathrm{cat} 2}-\omega_{3}^{-} c_{\mathrm{P}} \\
& 0=r_{2}=\omega_{2}^{+} c_{\text {cat1 }}-\left(\omega_{2}^{-}+\omega_{3}^{+}\right) c_{\text {cat2 }}+\omega_{3}^{-} c_{\mathrm{P}} \\
& 0=r_{1}=\omega_{1}^{+} c_{\mathrm{A}}-\left(\omega_{1}^{-}+\omega_{2}^{+}\right) c_{\text {cat1 }}+\omega_{2}^{-} c_{\text {cat2 }}
\end{aligned}
$$

Rearrangement of eq. A2 for an explicit expression of $c_{\text {cat2 }}$ results in eq. (A4):

$$
C_{\text {cat2 }}=\frac{\omega_{2}^{+} c_{\text {cat1 }}+\omega_{3}^{-} c_{\mathrm{P}}}{\left(\omega_{2}^{-}+\omega_{3}^{+}\right)}
$$

Rearrangement of eq. A3 for an explicit expression of $c_{\text {cat1 }}$ results in eq. (A5):

$$
c_{\text {cat1 }}=\frac{\omega_{1}^{+} c_{\mathrm{A}}+\omega_{2}^{-} c_{\text {cat2 }}}{\left(\omega_{1}^{-}+\omega_{2}^{+}\right)}
$$

Additionally eq. (A4) has to be insert in eq. (A5) and follows to eq. (A6)

$$
c_{\text {cat1 }}=\frac{\omega_{1}^{+} c_{\mathrm{A}}}{\left(\omega_{1}^{-}+\omega_{2}^{+}\right)}+\frac{\omega_{2}^{-}}{\left(\omega_{1}^{-}+\omega_{2}^{+}\right)} \frac{\omega_{2}^{+} c_{\text {cat1 }}+\omega_{3}^{-} c_{\mathrm{P}}}{\left(\omega_{2}^{-}+\omega_{3}^{+}\right)}
$$


Eq. A6 must be solved again for $c_{\text {cat1 }}$

$c_{\text {cat } 1}=\frac{\left(\omega_{2}^{-}+\omega_{3}^{+}\right) \omega_{1}^{+} c_{\mathrm{A}}+\omega_{2}^{-} \omega_{3}^{-} c_{\mathrm{P}}}{\omega_{2}^{+} \omega_{3}^{+}+\omega_{1}^{-} \omega_{3}^{+}+\omega_{1}^{-} \omega_{2}^{-}}$

Using the eqs. A4 and A7 and insert them in eq. A1, the rate approach can be re-written:

$$
r_{\mathrm{P}}=\frac{\omega_{3}^{+} \omega_{2}^{+}}{\left(\omega_{2}^{-}+\omega_{3}^{+}\right)} \frac{\left(\omega_{2}^{-}+\omega_{3}^{+}\right) \omega_{1}^{+} c_{\mathrm{A}}+\omega_{2}^{-} \omega_{3}^{-} c_{\mathrm{P}}}{\omega_{1}^{-} \omega_{2}^{-}+\omega_{1}^{-} \omega_{3}^{+}+\omega_{2}^{+} \omega_{3}^{+}}+\frac{\omega_{3}^{+} \omega_{3}^{-} c_{\mathrm{P}}}{\left(\omega_{2}^{-}+\omega_{3}^{+}\right)}-\omega_{3}^{-} c_{\mathrm{P}}
$$

Final rearrangements lead to eq. A9:

$$
r_{\mathrm{P}}=\frac{\omega_{1}^{+} \omega_{2}^{+} \omega_{3}^{+} c_{\mathrm{A}}}{\left(\omega_{2}^{+} \omega_{3}^{+}+\omega_{1}^{-} \omega_{3}^{+}+\omega_{1}^{-} \omega_{2}^{-}\right)}-\frac{\omega_{1}^{-} \omega_{2}^{-} \omega_{3}^{-} c_{\mathrm{P}}}{\left(\omega_{2}^{+} \omega_{3}^{+}+\omega_{1}^{-} \omega_{3}^{+}+\omega_{1}^{-} \omega_{2}^{-}\right)}
$$

This derivation has to be repeated for all catalyst species. For the intermediate 1 and 2 the derivation is only suggested in the following.

Reaction pathway: $\quad A \underset{\omega_{2}^{-}}{\stackrel{\omega_{2}^{+}}{\rightleftarrows}}$ (intermediate2) $\begin{gathered}\text { Catalyst } \\ \stackrel{\omega_{3}^{+}}{\rightleftarrows}\end{gathered}$ (free Catalyst) $\begin{gathered}\text { Catalyst } \\ \stackrel{\omega_{1}^{-}}{\rightleftarrows} P\end{gathered}$

$$
r_{\mathrm{P}}=\frac{\omega_{1}^{+} \omega_{2}^{+} \omega_{3}^{+} c_{\mathrm{A}}}{\left(\omega_{1}^{+} \omega_{3}^{+}+\omega_{1}^{+} \omega_{2}^{-}+\omega_{2}^{-} \omega_{3}^{-}\right)}-\frac{\omega_{1}^{-} \omega_{2}^{-} \omega_{3}^{-} c_{\mathrm{P}}}{\left(\omega_{1}^{+} \omega_{3}^{+}+\omega_{1}^{+} \omega_{2}^{-}+\omega_{2}^{-} \omega_{3}^{-}\right)}
$$

Reaction pathway: $\quad A \underset{\omega_{3}^{-}}{\stackrel{\omega_{3}^{+}}{\rightleftarrows}}$ (free Catalyst) $\begin{gathered}\text { Catalyst } \\ \stackrel{\omega_{1}^{+}}{\rightleftarrows}\end{gathered}$ (intermediate1) $\begin{gathered}\text { Catalyst } \\ \stackrel{\omega_{2}^{+}}{\rightleftarrows} P\end{gathered}$

$$
r_{\mathrm{P}}=\frac{\omega_{1}^{+} \omega_{2}^{+} \omega_{3}^{+} c_{\mathrm{A}}}{\left(\omega_{1}^{+} \omega_{2}^{+}+\omega_{2}^{+} \omega_{3}^{-}+\omega_{1}^{-} \omega_{3}^{-}\right)}-\frac{\omega_{1}^{-} \omega_{2}^{-} \omega_{3}^{-} c_{\mathrm{P}}}{\left(\omega_{1}^{+} \omega_{2}^{+}+\omega_{2}^{+} \omega_{3}^{-}+\omega_{1}^{-} \omega_{3}^{-}\right)}
$$

Using the denominators of the eqs. A9-A11, the complete Christiansen matrix is determined.

\section{References}

Affersholt-Allen, T., 2007. Market developments and industrial challenges for lactose and lactose derivatives, IDF Sympossium "Lactose and its Derivatives", Moscow.

Alander, M., Mättö, J., Kneifel, W., Johansson, M., Kögler, B., Crittenden, R., MattilaSandholm, T., Saarela, M., 2001. Effect of galacto-oligosaccharide supplementation on human faecal microflora and on survival and persistence of Bifidobacterium lactis Bb-12 in the gastrointestinal tract. International Dairy Journal 11, 817-825. 
Barz, T., López Cárdenas, D.C., Arellano Garcia, H., Wozny, G., 2013. Experimental evaluation of an approach to online redesign of experiments for parameter determination. AIChE Journal 59, 1981-1995.

Boon, M.A., Janssen, A.E.M., van 't Riet, K., 2000. Effect of temperature and enzyme origin on the enzymatic synthesis of oligosaccharides. Enzyme and Microbial Technology 26, 271281.

Burth, M., Verghese, G.C., Vélez-Reyes, M., 1999. Subset selection for improved parameter estimation in on-line identification of a synchronous generator. IEEE Transactions on Power Systems 14, 218-225.

Chen, C.W., Ou-Yang, C.-C., Yeh, C.-W., 2003. Synthesis of galactooligosaccharides and transgalactosylation modeling in reverse micelles. Enzyme and Microbial Technology 33, 497-507.

Chonan, O., Matsumoto, K., Watanuki, M., 1995. Effect of galactooligosaccharides on calcium absorption and preventing bone loss in ovariectomized rats. Bioscience, biotechnology, and biochemistry 59, 236-239.

Christiansen, J.A., 1953. The Elucidation of Reaction Mechanisms by the Method of Intermediates in Quasi-Stationary Concentrations, in: W.G. Frankenburg, V.I.K., Rideal, E.K. (Eds.), Advances in Catalysis. Academic Press, pp. 311-353.

Davis, L.M.G., Martínez, I., Walter, J., Hutkins, R., 2010. A dose dependent impact of prebiotic galactooligosaccharides on the intestinal microbiota of healthy adults. International Journal of Food Microbiology 144, 285-292.

Fink, M., Attarian, A., Tran, H., 2007. Subset selection for parameter estimation in an HIV model. PAMM 7, 1121501-1121502.

Fischer, C., Kleinschmidt, T., 2015. Synthesis of galactooligosaccharides using sweet and acid whey as a substrate. International Dairy Journal 48, 15-22.

Gänzle, M.G., Haase, G., Jelen, P., 2008. Lactose: Crystallization, hydrolysis and valueadded derivatives. International Dairy Journal 18, 685-694.

Geiger, B., Nguyen, H.-M., Wenig, S., Nguyen, H.A., Lorenz, C., Kittl, R., Mathiesen, G., Eijsink, V.G.H., Haltrich, D., Nguyen, T.-H., 2016. From by-product to valuable components: Efficient enzymatic conversion of lactose in whey using $\beta$-galactosidase from Streptococcus thermophilus. Biochemical Engineering Journal.

Guimarães, P.M., Teixeira, J.A., Domingues, L., 2010. Fermentation of lactose to bio-ethanol by yeasts as part of integrated solutions for the valorisation of cheese whey. Biotechnology Advances 28, 375-384.

Helfferich, F.G., 2004. Kinetics of multistep reactions. Elsevier.

Huber, R., Kurz, G., Wallenfels, K., 1976. A quantitation of the factors which affect the hydrolase and transgalactosylase activities of $\beta$-galactosidase (E. coli) on lactose. Biochemistry 15, 1994-2001.

Intanon, M., Arreola, S.L., Pham, N.H., Kneifel, W., Haltrich, D., Nguyen, T.-H., 2014. Nature and biosynthesis of galacto-oligosaccharides related to oligosaccharides in human breast milk. FEMS microbiology letters 353, 89-97.

Ito, M., Deguchi, Y., Miyamori, A., Matsumoto, K., Kikuchi, H., Kobayashi, Y., Yajima, T., Kan, T., 1990. Effects of administration of galactooligosaccharides on the human faecal 
microflora, stool weight and abdominal sensation. Microbial Ecology in Health and Disease $3,285-292$.

Jörke, A., Triemer, S., Seidel Morgenstern, A., Hamel, C., 2015. Kinetic Investigation Exploiting Local Parameter Subset Selection: Isomerization of 1 Decene using a Rh Biphephos Catalyst. Chemie Ingenieur Technik 87, 713-725.

Kiedorf, G., Hoang, D.M., Müller, A., Jörke, A., Markert, J., Arellano-Garcia, H., SeidelMorgenstern, A., Hamel, C., 2014. Kinetics of 1-dodecene hydroformylation in a thermomorphic solvent system using a rhodium-biphephos catalyst. Chemical Engineering Science 115, 31-48.

Kiedorf, G., Wolff, T., Seidel Morgenstern, A., Hamel, C., 2016. Kinetic Analysis of the Hydrocarbon Total Oxidation Using Individually Measured Adsorption Isotherms. Chemie Ingenieur Technik.

Kim, C.S., Ji, E.-S., Oh, D.-K., 2004. A new kinetic model of recombinant $\beta$-galactosidase from Kluyveromyces lactis for both hydrolysis and transgalactosylation reactions. Biochemical and biophysical research communications 316, 738-743.

Lamsal, B.P., 2012. Production, health aspects and potential food uses of dairy prebiotic galactooligosaccharides. Journal of the Science of Food and Agriculture 92, 2020-2028.

Mahoney, R.R., 1998. Galactosyl-oligosaccharide formation during lactose hydrolysis: A review. Food Chemistry 63, 147-154.

Marin, G., Yablonsky, G.S., 2011. Kinetics of chemical reactions. John Wiley \& Sons.

Martínez-Villaluenga, C., Cardelle-Cobas, A., Corzo, N., Olano, A., Villamiel, M., 2008. Optimization of conditions for galactooligosaccharide synthesis during lactose hydrolysis by $\beta$-galactosidase from Kluyveromyces lactis (Lactozym 3000 L HP G). Food Chemistry 107, 258-264.

Meyer, T.S.M., Miguel, Â.S.M., Fernández, D.E.R., Ortiz, G.M.D., 2015. Biotechnological Production of Oligosaccharides-Applications in the Food Industry.

Murzin, D.Y., Salmi, T., 2005. Catalytic kinetics. Elsevier.

Neri, D.F.M., Balcão, V.M., Costa, R.S., Rocha, I.C.A.P., Ferreira, E.M.F.C., Torres, D.P.M., Rodrigues, L.R.M., Carvalho Jr, L.B., Teixeira, J.A., 2009. Galacto-oligosaccharides production during lactose hydrolysis by free Aspergillus oryzae $\beta$-galactosidase and immobilized on magnetic polysiloxane-polyvinyl alcohol. Food Chemistry 115, 92-99.

Palai, T., Bhattacharya, P.K., 2013. Kinetics of lactose conversion to galactooligosaccharides by $\beta$-galactosidase immobilized on PVDF membrane. Journal of Bioscience and Bioengineering 115, 668-673.

Palai, T., Kumar, A., Bhattacharya, P.K., 2015. Kinetic studies and model development for the formation of galacto-oligosaccharides from lactose using synthesized thermo-responsive bioconjugate. Enzyme and Microbial Technology 70, 42-49.

Palai, T., Kumar, A., Bhattacharya, P.K., 2016. Enzyme immobilization/bioconjugation in producing galactio-oligosaccharidies from lactose: developments of kinetic models and bioreactors. Materials Today: Proceedings 3, 3568-3586.

Playne, M., Crittenden, R., 2009. Galacto-oligosaccharides and other products derived from lactose, Advanced dairy chemistry. Springer, pp. 121-201. 
Prenosil, J., Stuker, E., Bourne, J., 1987. Formation of oligosaccharides during enzymatic lactose hydrolysis and their importance in a whey hydrolysis process: Part II: Experimental. Biotechnology and Bioengineering 30, 1026-1031.

Roberfroid, M., Gibson, G., Delzenne, N., 1993. The biochemistry of oligofructose, a nondigestible fiber: an approach to calculate its caloric value. Nutrition reviews 51, 137-146.

Roberfroid, M., Gibson, G.R., Hoyles, L., McCartney, A.L., Rastall, R., Rowland, I., Wolvers, D., Watzl, B., Szajewska, H., Stahl, B., 2010. Prebiotic effects: metabolic and health benefits. British Journal of Nutrition 104, S1-S63.

Sako, T., Matsumoto, K., Tanaka, R., 1999. Recent progress on research and applications of non-digestible galacto-oligosaccharides. International Dairy Journal 9, 69-80.

Sangwan, V., Tomar, S., Singh, R., Singh, A., Ali, B., 2011. Galactooligosaccharides: novel components of designer foods. Journal of food science 76, R103-R111.

Schoterman, M., 2007. Health promoting effects of prebiotic galacto-oligosaccharides, IDF Symposium "Lactose and its Derivatives", Moscow.

Shadid, R., Haarman, M., Knol, J., Theis, W., Beermann, C., Rjosk-Dendorfer, D., Schendel, D.J., Koletzko, B.V., Krauss-Etschmann, S., 2007. Effects of galactooligosaccharide and long-chain fructooligosaccharide supplementation during pregnancy on maternal and neonatal microbiota and immunity - a randomized, double-blind, placebo-controlled study. The American journal of clinical nutrition 86, 1426-1437.

Sigma-Aldrich Inc., 2005. b-Galactosidase from E. coli, recombinant overexpresed in E. coli - Datasheet.

Smart, J.B., 1991. Transferase reactions of the $\beta$-galactosidase from Streptococcus thermophilus. Applied Microbiology and Biotechnology 34, 495-501.

Toch, K., Thybaut, J.W., Marin, G.B., 2015. A systematic methodology for kinetic modeling of chemical reactions applied to $\mathrm{n}$ hexane hydroisomerization. AIChE Journal 61, 880-892.

Torres, D.P., Gonçalves, M.d.P.F., Teixeira, J.A., Rodrigues, L.R., 2010. Galacto oligosaccharides: production, properties, applications, and significance as prebiotics. Comprehensive Reviews in Food Science and Food Safety 9, 438-454.

Tzortzis, G., Vulevic, J., 2009. Galacto-oligosaccharide prebiotics, Prebiotics and probiotics science and technology. Springer, pp. 207-244.

van den Heuvel, E.G., Schoterman, M.H., Muijs, T., 2000. Transgalactooligosaccharides stimulate calcium absorption in postmenopausal women. The Journal of nutrition 130, 29382942.

Vera, C., Córdova, A., Aburto, C., Guerrero, C., Suárez, S., Illanes, A., 2016. Synthesis and purification of galacto-oligosaccharides: state of the art. World Journal of Microbiology and Biotechnology 32, 197.

Vera, C., Guerrero, C., Illanes, A., 2011. Determination of the transgalactosylation activity of Aspergillus oryzae $\beta$-galactosidase: effect of $\mathrm{pH}$, temperature, and galactose and glucose concentrations. Carbohydrate Research 346, 745-752. 